\title{
Robust late twenty-first century shift in the regional monsoons in RegCM-CORDEX simulations
}

\author{
Moetasim Ashfaq ${ }^{1}$ (D) Tereza Cavazos ${ }^{2} \cdot$ Michelle Simões Reboita ${ }^{3}$. José Abraham Torres-Alavez ${ }^{4}$ Eun-Soon $\mathrm{Im}^{5}$. \\ Christiana Funmilola Olusegun ${ }^{6} \cdot$ Lincoln Alves $^{7} \cdot$ Kesondra Key $^{1} \cdot$ Mojisola O. Adeniyi ${ }^{8} \cdot$ Moustapha Tall $^{9}$. \\ Mouhamadou Bamba Sylla ${ }^{10}$. Shahid Mehmood ${ }^{1,11}$. Qudsia Zafar ${ }^{12}$. Sushant Das ${ }^{4}$. Ismaila Diallo ${ }^{13}$. \\ Erika Coppola ${ }^{4} \cdot$ Filippo Giorgi $^{4}$
}

Received: 8 January 2020 / Accepted: 19 May 2020 / Published online: 4 June 2020

(c) The Author(s) 2020

\begin{abstract}
We use an unprecedented ensemble of regional climate model (RCM) projections over seven regional CORDEX domains to provide, for the first time, an RCM-based global view of monsoon changes at various levels of increased greenhouse gas (GHG) forcing. All regional simulations are conducted using RegCM4 at a $25 \mathrm{~km}$ horizontal grid spacing using lateral and lower boundary forcing from three General Circulation Models (GCMs), which are part of the fifth phase of the Coupled Model Inter-comparison Project (CMIP5). Each simulation covers the period from 1970 through 2100 under two Representative Concentration Pathways (RCP2.6 and RCP8.5). Regional climate simulations exhibit high fidelity in capturing key characteristics of precipitation and atmospheric dynamics across monsoon regions in the historical period. In the future period, regional monsoons exhibit a spatially robust delay in the monsoon onset, an increase in seasonality, and a reduction in the rainy season length at higher levels of radiative forcing. All regions with substantial delays in the monsoon onset exhibit a decrease in pre-monsoon precipitation, indicating a strong connection between pre-monsoon drying and a shift in the monsoon onset. The weakening of latent heat driven atmospheric warming during the pre-monsoon period delays the overturning of atmospheric subsidence in the monsoon regions, which defers their transitioning into deep convective states. Monsoon changes under the RCP2.6 scenario are mostly within the baseline variability.
\end{abstract}

Moetasim Ashfaq

mashfaq@ornl.gov

1 Computational Sciences and Engineering Division, Oak Ridge National Laboratory, Oak Ridge, TN, USA

2 Center for Scientific Research and Higher Education of Ensenada, Ensenada, Baja California, Mexico

3 Federal University of Itajubá, Itajubá, MG, Brazil

4 Abdus Salam International Centre for Theoretical Physics, Trieste, Italy

5 Department of Civil and Environmental Engineering/Division of Environment and Sustainability, The Hong Kong University of Science and Technology, Kowloon, Hong Kong

6 Centre for Atmospheric Research, National Space Research and Development Agency, Anyigba, Nigeria
7 National Institute for Space Research, Earth System Science Center, São José dos Campos, São Paulo, Brazil

8 Department of Physics, University of Ibadan, Ibadan, Nigeria

9 Laboratoire de Physique de L'Atmosphère Et de L'Océan-Siméon Fongang, Ecole Supérieure Polytechnique, Université Cheikh Anta Diop, Dakar-Fann, PO Box: 5085, Dakar, Senegal

10 African Institute for Mathematical Sciences, AIMS Rwanda Center, P. O. Box, 7150 Kigali, Rwanda

11 Research Center for Environmental Changes, Taiwan International Graduate Program, Academia Sinica, Taipei, Taiwan

12 Global Change Impact Studies Centre, Islamabad, Pakistan

13 Departement of Geography, University of California-Los Angeles, Los Angeles, CA, USA 


\section{Introduction}

From the highest peaks in the Himalayas to the largest tropical forests in the Amazon, from the biggest wetlands in Asia to the richest flora and fauna of Northern Australia, and from the grazing lands of Mexico and Africa to the semi-arid rainfed agriculture across all of these continents, the latitudinal oscillation of the Inter Tropical Convergence Zone (ITCZ) between the onset and demise of global monsoons potentially influences every livelihood of natural and human systems. Over two-thirds of the global population and nearly the world's entire impoverished communities reside within monsoon impacted areas (Beegle et al. 2013), which receive more than half of their annual precipitation during their respective monsoon seasons. More importantly, many of these countries are among the world's most vulnerable regions where a changing climate is already posing serious challenges. For instance, many of the top ten most impacted countries by extreme weather events are within monsoon regions (Eckstein et al. 2020).

A monsoon system is generally characterized by the seasonal wind reversal in the lower atmosphere (Ramage 1971) and a strong large-scale vertical wind shear as a result of differential heating between continents and oceans ( $\mathrm{Li}$ and Yanai 1996; Turrent and Cavazos 2009; Webster et al. 1998). However, not every region that receives monsoon precipitation clearly witnesses a seasonal reversal of winds, such as in the South American monsoon, where trade winds dominate during the rainy season (Carvalho and Cavalcanti 2016). As the Earth rotates around the sun on its annual cycle, the ITCZ changes its location from the austral summer in the Southern Hemisphere (SH) to the boreal summer in the Northern Hemisphere (NH). Such a periodicity partially drives the regularity in the arrival and departure of the rainy season over each impacted region. The intensity, duration and spatial distribution of regional monsoon precipitation is further influenced by many regional forcing mechanisms, such as topographic controls on diabatic heating ( $\mathrm{Li}$ and Yanai 1996; Rodwell and Hoskins 2001), the nature of land-atmosphere-ocean interactions (Ashfaq et al. 2017; Grodsky and Carton 2001; Misra 2008; Sun et al. 2019; Thorncroft et al. 2011; Yasunari 2007), the presence of east-west ocean-basin contrasts (Wang et al. 2003, 2012), and the structure of monsoonal lows (Hurley and Boos 2015). These regional-scale mechanisms interact with large-scale natural forcing, such as the El Niño Southern Oscillation, the Pacific Decadal Oscillation, and the Atlantic Multidecadal Oscillation, at varying timescales, which result in intra-seasonal to decadal variations in monsoon circulation and precipitation patterns (e.g. An et al. 2015; Webster et al. 1998).
In recent decades, the global monsoon system has witnessed heterogenous trends in the timing, strength and seasonal precipitation magnitudes at regional scales, including an earlier onset over South Asia and Southeast Asia (Bollasina et al. 2014; Bridhikitti 2019), increasing precipitation trends over Australia (Gallego et al. 2017), a delayed onset over South America (Marengo et al. 2011), and declining precipitation trends over Africa, East Asia, and North America (Cavazos et al. 2020; Zhan et al. 2018; Zhu et al. 2011). While changes over the American monsoons are partially attributed to the natural variability of the climate system (Arias et al. 2012; Castro et al. 2001; Cavazos et al. 2020), anthropogenic aerosols are considered one of the major drivers of recent fluctuations in Asian monsoons (Ganguly et al. 2012; Jiang et al. 2013; Polson et al. 2014). Similarly, drought and recovery of the West African monsoon has been attributed to aerosols and greenhouse gas concentrations (Biasutti 2019; Dong and Sutton 2015). However, a robust understanding towards the causes of variations in regional monsoon systems remain challenging due to uncertainties in the observations and deficiencies in the current generation of General Circulation Models (GCMs) (Biasutti 2019; Pascale et al. 2017; Singh et al. 2019).

GCMs have considerably improved over the years in the representation of global monsoon systems. In spite of this, significant inconsistences still exist at regional scales over a number of monsoon regions. For instance, most of the GCMs that are part of the 5th phase of the Coupled Models Inter-comparison Project (CMIP5; Taylor et al. 2012) are unable to accurately simulate the monsoon onset, the frequency and trajectory of monsoon depressions, and the spatial distribution of seasonal precipitation over the South Asian monsoon region (e.g. Ashfaq et al. 2017; Rastogi et al. 2018). Biases exist in GCM simulations of the monsoon onset over Australia (Zhang 2010), the monsoon retreat over the North American monsoon region (Cook and Seager 2013; Geil et al. 2013), the monsoon timing and variability over West Africa (Dunning et al. 2017; Roehrig et al. 2013), and the spatial precipitation distribution over the African, South American and the East and Southeast Asian monsoon regions (Mariotti et al. 2014; Sperber et al. 2013; Yin et al. 2013). Given the challenges in the simulation of regional-scale monsoon characteristics, CMIP5 models exhibit variable confidence in the simulation of future monsoon responses at regional scales (Christensen et al. 2013). While global monsoons as an aggregate are likely to strengthen in terms of precipitation intensity and weaken in terms of circulation strength (Kitoh et al. 2013; Lee and Wang 2014), there is medium to low confidence in the precipitation amounts over the American and Asian monsoons (Bukovsky et al. 2013; Christensen et al. 2013; Colorado-Ruiz et al. 2018; Pascale et al. 2017, 2019) and in the timing of the monsoon onset over the North American 
and West African monsoon regions (Christensen et al. 2013; Diallo et al. 2014; Mariotti et al. 2014; Pascale et al. 2019).

The growing acknowledgement that monsoon climates are changing due to natural and anthropogenic influences has produced a mounting demand for regional climate change information over tropical regions. Moreover, within the context of negotiations to limit global warming to a $2{ }^{\circ} \mathrm{C}$ warming level, it is imperative to understand regional monsoon responses at various levels of increases in radiative forcing. Presently, due to the limitations in the representation of regional monsoons in GCM simulations (Ashfaq et al. 2017; Biasutti et al. 2018; Pascale et al. 2019; Sperber et al. 2013), regional and local-scale studies for understanding the impacts of changing monsoonal characteristics on natural and human systems increasingly rely on the dynamical downscaling of GCMs through their use as initial and boundary forcing in Regional Climate Models (RCMs; Giorgi and Gutowski 2015). There are numerous studies that demonstrate the added value of RCMs in the simulation of seasonal mean precipitation (Fotso-Nguemo et al. 2017; Giorgi 2019; Mariotti et al. 2014; Racherla et al. 2012; Torma et al. 2015), the onset and demise over monsoon regions (Ashfaq et al. 2009; Diallo et al. 2014; Sylla et al. 2013), and the intensity of hot and wet extremes (Li 2017; Qiu et al. 2019), due to their finer grid spacing and their flexibility of region-specific parametrization tuning.

In recent decades, RCMs have been extensively utilized to regionally refine GCM projections over terrestrial regions, particularly within the framework of the Coordinated Regional Downscaling Experiment (CORDEX; Giorgi et al. 2009). Among these RCMs, the International Centre for Theoretical Physics (ICTP) Regional Climate Model ( $\operatorname{RegCM}$ ) is one of the most widely used models for climate change studies (Ambrizzi et al. 2019; Ashfaq et al. 2009, 2016; Bukovsky et al. 2013; Diallo et al. 2016; Diffenbaugh et al. 2011; Fuentes-Franco et al. 2014; Gao et al. 2017; Giorgi et al. 2012; Mariotti et al. 2014; Martinez-Castro et al. 2006; Reboita et al. 2014; Sylla et al. 2015).

Recently, the version 4 of the RegCM system, RegCM4 (Giorgi et al. 2012) has been used to produce a set of regional projections over nine CORDEX domains at $25 \mathrm{~km}$ grid spacing under the framework of the CORDEX-CORE initiative (Giorgi and Gutowski 2015). In this study, we use this unprecedented high-resolution ensemble of simulations over seven of the nine CORDEX domains that include all major monsoon regions of the world under two Representative Concentration Pathways (RCP2.6 and RCP8.5) to investigate regional monsoon responses to increases in radiative forcing during the twenty-first century. Our analyses focus on seasonal characteristics of regional monsoons, their expected changes in onset and demise of precipitation, and on the commonality of regional monsoon responses across multiple domains. Furthermore, our comparison of simulations driven with the lowest
(RCP2.6) and highest (RCP8.5) concentration pathways provide an insight into the consequences should greenhouse gas concentrations continue to escalate along their current trajectory, as well as the benefits of emission stabilization.

\section{Data and methods}

\subsection{Datasets}

We utilize dynamically downscaled simulations over seven CORDEX domains: Africa, Australasia, East Asia, Central America, South America, South Asia, and Southeast Asia (Fig. 1). For every region, we employ ICTP RegCM4 to downscale three CMIP5 GCMs that exhibit adequate region-specific skills. Table 1 shows the details of RegCM4 domains, selected parameterizations, and driving GCMs over each region. Each RegCM4 configuration utilizes $25 \mathrm{~km}$ horizontal grid spacing and 23 levels in the vertical over a domain that follows the latitudinal and longitudinal extent recommended by the CORDEX-CORE initiative. For GCM downscaling, RegCM4 simulations are conducted in a transient mode from 1970 to 2100 with annually varying greenhouse gas (GHG) forcing. For the historical period (1970-2005), RegCM4 uses observed GHG forcing. For the future period (2006-2100), RegCM4 is forced with projected GHG forcing RCP2.6 and RCP8.5, which represent lower and higher end radiative forcing scenarios, respectively (van Vuuren et al. 2011). Both future period integrations are initialized using restart data from the last time step of the historical period integration.

For model comparisons with observations and reanalysis, we use (1) $1^{\circ}$ daily precipitation from the Global Precipitation Climatology Project (GPCP) version 1.2 (Huffman et al. 2016), (2) monthly precipitation from $0.5^{\circ}$ Climate Research Unit Timeseries (CRU TS) version 4.03 (Harris et al. 2014), and (3) monthly atmospheric divergence, winds and temperatures from the $0.25^{\circ}$ European Reanalysis $5^{\circ}$ (ERA5) reanalysis data (C3S 2017).

\subsection{Methods}

We utilize the Feng et al. (2013) analysis framework to calculate a dimensionless seasonality index (hereafter seasonality), relative entropy, and the timing of centroid at each grid point. For each hydrological year (October-September), we calculate the relative entropy at each grid point using the following expression:

$R E_{y}=\sum_{m=1}^{12} P b_{y, m} \log _{2}\left[\frac{P b_{y, m}}{q_{m}}\right]$

where $P b_{y, m}$ represents the precipitation probability in a month $m$ of year $y$, calculated as the fraction of annual 


\section{RegCM CORDEX Domains and Monoon Regions}

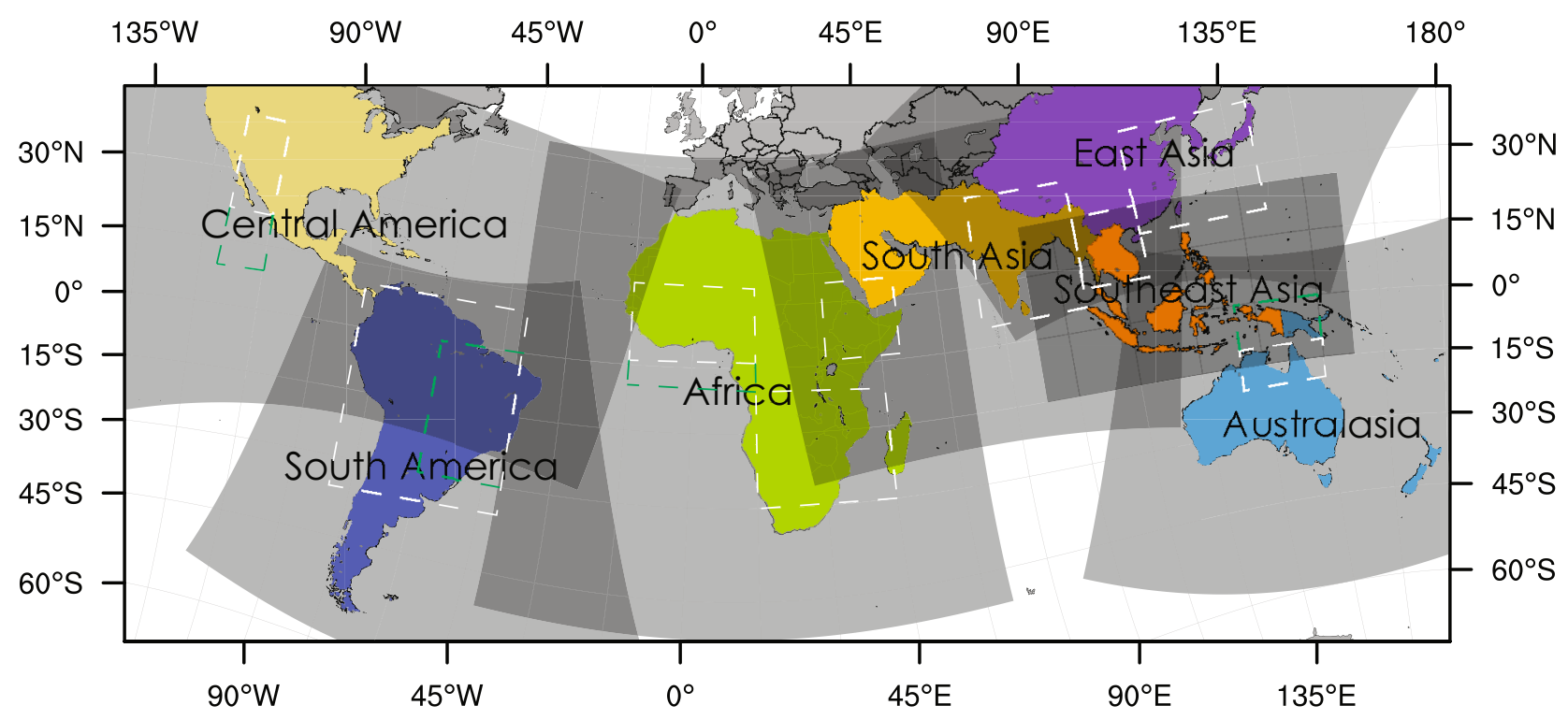

Fig. 1 Different RegCM CORDEX domains used in the analyses. The colored land area within each domain reflects the region that has been used from each RegCM integration for spatial plots. Boxes represent areas used for various zonal average analyses

precipitation in year $y$ falling in the month $m . q_{m}$ represents the uniform distribution and has value of $\frac{1}{12}$ for all months. Relative entropy provides a measure of distance between the simulated monthly precipitation and the uniform distribution. Higher values of entropy suggest the non-uniformity of monthly precipitation in a given year, implying that precipitation is more distributed around the wet season. Subsequently, the seasonality of precipitation is calculated as the product of relative entropy and the annual mean precipitation. In order for the results to be comparable across different CORDEX domains, datasets (observations, model simulations), and simulation periods (historical, future), we normalize the results using the maximum precipitation $\left(P_{\max }\right)$ found over all datasets and simulation periods. Therefore, the expression for seasonality can be written as:

$S_{y}=R E_{y} \times \frac{P_{y}}{P_{\max }}$

The maximum value of seasonality can be reached if a grid point receives $P_{\max }$ in a single month, which implies that regions with low annual precipitation will exhibit low seasonality even if the precipitation distribution across the months is highly nonuniform. Furthermore, we calculate the timing of centroid using the first moment of monthly mean precipitation, which corresponds to the timing when $50 \%$ of the annual precipitation is reached in a hydrological year. Further details of the methodology and mathematical expressions can be referred to Feng et al. (2013).
Additionally, we calculate the monsoon onset pentad (5-day average) at each grid point following a methodology adopted from Bombardi and Carvalho (2009). For each analysis time period, we use the climatological pentad time series at each grid point to calculate the sum using the following expression:

$S($ pentad $)=\sum_{n=\text { pentad }}{ }_{\text {pentad }}\left(P_{n}-\bar{P}\right)$

where $\bar{P}$ represents the climatological annual mean and $P_{n}$ represents the $n t h$ pentad of precipitation. Subsequently, the monsoon onset and monsoon demise at each grid point are defined as the pentad after the minimum $\mathrm{S}$ and the pentad after the maximum $S$, respectively. Our approach is relatively simple and slightly different when compared to Bombardi and Carvalho (2009), yet it yields similar results when applied to the climatological data.

We utilize 1995-2014 as the reference historical period for comparisons with observations and reanalysis, and for the calculation of future changes in the twenty-first century. The reference period during 2006-2014 is taken from the RCP8.5 simulations. There is not much difference between RCP8.5 and RCP2.6 radiative forcing, and corresponding RegCM4 simulations for this time period. Therefore, no noticeable impact on future changes are expected due to this methodological choice. We use two 20-year time slices from the RCP2.6 and RCP8.5 model integrations to calculate changes in the mid-century (2041-2060) and the late century 
Table 1 RegCM4 configuration over various CORDEX domains

\begin{tabular}{|c|c|c|c|}
\hline Region & Physics Schemes & Parameterization & Driving GCMs \\
\hline $\begin{array}{l}\text { Africa } \\
500 \times 480 \\
(25 \mathrm{~km})\end{array}$ & $\begin{array}{l}\text { Boundary Layer } \\
\text { Cumulus (Land) } \\
\text { Cumulus (Ocean) } \\
\text { Microphysics } \\
\text { Ocean Flux }\end{array}$ & $\begin{array}{l}\text { Holtslag et al. (1990) } \\
\text { Tiedtke (1996) } \\
\text { Kain and Fritsch (1990) } \\
\text { SUBEX (Pal et al. 2000) } \\
\text { Zeng et al. (1998) }\end{array}$ & $\begin{array}{l}\text { HadGEM2-ES (Jones et al. 2011) } \\
\text { MPI-ESM-MR (Stevens et al. 2013) } \\
\text { NorESM1-M (Bentsen et al. 2013) }\end{array}$ \\
\hline $\begin{array}{l}\text { Australasia } \\
338 \times 416(25 \mathrm{~km})\end{array}$ & $\begin{array}{l}\text { Boundary Layer } \\
\text { Cumulus (Land) } \\
\text { Cumulus (Ocean) } \\
\text { Microphysics } \\
\text { Ocean Flux }\end{array}$ & $\begin{array}{l}\text { Holtslag et al. (1990) } \\
\text { Tiedtke } \\
\text { Tiedtke } \\
\text { SUBEX } \\
\text { Zeng }\end{array}$ & HadGEM2-ES MPI-ESM-MR NorESM1-M \\
\hline $\begin{array}{l}\text { Central America } \\
573 \times 373(25 \mathrm{~km})\end{array}$ & $\begin{array}{l}\text { Boundary Layer } \\
\text { Cumulus (Land) } \\
\text { Cumulus (Ocean) } \\
\text { Microphysics } \\
\text { Ocean Flux }\end{array}$ & $\begin{array}{l}\text { Holtslag et al. (1990) } \\
\text { Emanuel et al. (1991) } \\
\text { Kain-Fritsch } \\
\text { SUBEX } \\
\text { Zeng et al. }\end{array}$ & $\begin{array}{l}\text { HadGEM2-ES MPI-ESM-MR } \\
\text { GFDL-ESM2M (Donner et al. 2011) }\end{array}$ \\
\hline $\begin{array}{l}\text { South America } \\
363 \times 333(25 \mathrm{~km})\end{array}$ & $\begin{array}{l}\text { Boundary Layer } \\
\text { Cumulus (Land) } \\
\text { Cumulus (Ocean) } \\
\text { Microphysics } \\
\text { Ocean Flux }\end{array}$ & $\begin{array}{l}\text { Holtslag et al. (1990) } \\
\text { Tiedtke } \\
\text { Kain-Fritsch } \\
\text { SUBEX } \\
\text { Zeng }\end{array}$ & HadGEM2-ES MPI-ESM-MR NorESM1-M \\
\hline $\begin{array}{l}\text { South Asia } \\
429 \times 337(25 \mathrm{~km})\end{array}$ & $\begin{array}{l}\text { Boundary Layer } \\
\text { Cumulus (Land) } \\
\text { Cumulus (Ocean) } \\
\text { Microphysics } \\
\text { Ocean Flux }\end{array}$ & $\begin{array}{l}\text { UW PBL (Bretherton et al. 2004) } \\
\text { Emanuel } \\
\text { Tiedtke } \\
\text { SUBEX } \\
\text { Zeng et al. }\end{array}$ & $\begin{array}{l}\text { HadGEM2-ES MPI-ESM-MR MIROC5 } \\
\text { (Watanabe et al. 2010) }\end{array}$ \\
\hline $\begin{array}{l}\text { Southeast Asia } \\
338 \times 192 \\
(25 \mathrm{~km})\end{array}$ & $\begin{array}{l}\text { Boundary Layer } \\
\text { Cumulus (Land) } \\
\text { Cumulus (Ocean) } \\
\text { Microphysics } \\
\text { Ocean Flux }\end{array}$ & $\begin{array}{l}\text { Holtslag et al. (1990) } \\
\text { Tiedtke } \\
\text { Tiedtke } \\
\text { SUBEX } \\
\text { Zeng }\end{array}$ & HadGEM2-ES MPI-ESM-MR NorESM1-M \\
\hline $\begin{array}{l}\text { East Asia } \\
384 \times 250 \\
(25 \mathrm{~km})\end{array}$ & $\begin{array}{l}\text { Boundary Layer } \\
\text { Cumulus (Land) } \\
\text { Cumulus (Ocean) } \\
\text { Microphysics } \\
\text { Ocean Flux }\end{array}$ & $\begin{array}{l}\text { Holtslag et al. (1990) } \\
\text { Emanuel } \\
\text { Emanuel } \\
\text { SUBEX } \\
\text { Zeng }\end{array}$ & HadGEM2-ES MPI-ESM-MR NorESM1-M \\
\hline
\end{tabular}

(2080-2099) period. All results are shown as an ensemble mean of three ensemble members over each domain while the robustness of future changes is being tested using the baseline variability as a threshold at each grid point. The late century period (2080-2099) changes over Africa are based on the downscaling of only two GCMs (HadGEM2-ES and NorESM1-M, Table 1), since the third ensemble member was not available at the time of analyses.

\section{Results}

\subsection{Historical evaluation of monsoon regions}

Despite regional differences among monsoon regions, such as the timing of monsoon onset and demise, the magnitude of rainy season precipitation, and the percent contribution of monsoonal rains to each annual mean, every monsoon region shares the fundamental characteristic of an uneven distribution of precipitation throughout the year. Therefore, monsoon regions are expected to display a strong seasonality in precipitation distribution. Given this fact, we analyze the seasonal characteristics of precipitation, including 
seasonality, relative entropy, and the timing of centroid, over each monsoon domain, both in the observations and the RegCM4 ensemble mean, during the historical period (1995-2014; Fig. 2). As expected, every monsoon region displays high values of seasonality in the observations (Fig. 2a), with the largest values over West Africa, South Asia, and parts of the Amazon. These large values of seasonality are mainly driven by the large fraction of annual precipitation during the monsoon season, which is reflected in the high magnitudes of relative entropy (Fig. 2c).

The timing of centroid occurs mostly around February in the austral summer over the monsoon regions in the $\mathrm{SH}$ and around July in the boreal summer over the monsoon regions in the $\mathrm{NH}$, which generally corresponds to peak monsoon precipitation over each region. However, each monsoon region shows spatial variations in the timing of centroid (Fig. 2e), suggesting that identical periods cannot be fully representative of the peak precipitation season over a monsoon region. Therefore, instead of using a fixed period as the core rainy season over each hemisphere, we define a three-month long period as the peak of the monsoon season over each grid point spanning from a month before the peak precipitation month to the month after the peak precipitation month in the observations. Precipitation during these

\section{Precipitation Characteristics over Monsoon Regions Reference Period (1995 to 2014)}
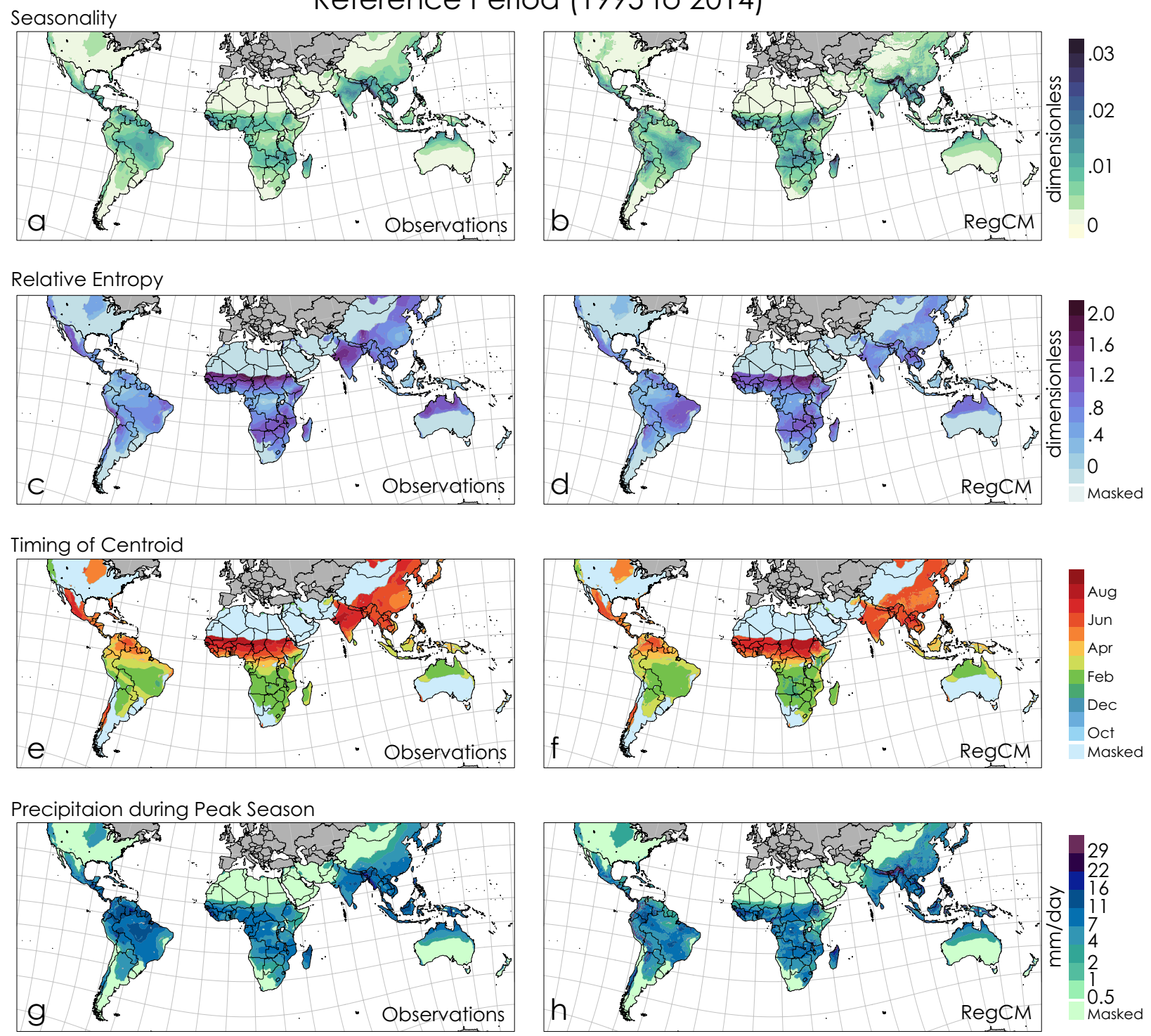

Fig. 2 Comparison between the CRU observations and the RegCM ensemble mean during the 1995-2014 period. Seasonality (a, b), relative entropy $(\mathbf{c}, \mathbf{d})$, timing of centroid $(\mathbf{e}, \mathbf{f})$, peak season precipitation $(\mathbf{g}, \mathbf{h})$. Values are masked in the bottom three rows where seasonality is $<0.025$ 
three months reflects monsoon precipitation over each grid point (Fig. 2g).

The RegCM4 ensemble simulates the smooth latitudinal transition of the monsoon seasons from the $\mathrm{SH}$ to the $\mathrm{NH}$ and vice versa in the Americas, Africa, and from Australia to Asia (Fig. 2f). In all cases, the RegCM4 captures the spatial patterns of the four measures of monsoon season characteristics effectively. However, there are a few exceptions where the RegCM4 simulated magnitudes differ from the observed. For instance, the RegCM4 ensemble overestimates (underestimates) seasonality (relative entropy) over higher elevations, such as the Himalayas in Asia, the Guinea Highlands in West Africa and the Andes in South America. This can be attributed to the model tendency to produce excessive convectively driven orographic precipitation. However, it should be noted that CRU may also have deficiencies over mountainous regions due to the lack of high elevation stations in those areas (Cavazos et al. 2020; New et al. 1999; Nijssen et al. 2001; Sylla et al. 2013). Relative entropy may exhibit biases if the model exhibits wet or dry biases during the monsoon season, such as lower relative entropy and drier than observed seasonal precipitation over parts of South Asia and Australia and higher relative entropy and wetter than observed seasonal precipitation over parts of South America. Additionally, South Asia exhibits earlier than observed timing of centroid over some areas, which reflects an overall dry bias in annual precipitation.

We also compare the pentad timing of the monsoon onset and demise over each monsoon region (Fig. 3), which are generally complementary to the timing of centroid (Fig. 2e-f). The separation of the NH and SH summer monsoon regions are clearly seen in the timing of centroid (Fig. 2e-f), and in the timing of monsoon onset and demise (Fig. 3), which is simulated well in the RegCM4 ensemble mean. The earliest monsoon onset in the $\mathrm{SH}$ is found over parts of the Amazon, and Southern Africa in early October, which gradually progresses eastward to cover entire monsoon regions by mid-December. The earliest monsoon demise in the SH appears over parts of Australia in late February, and by the beginning of May, the rainy season fully retreats from the $\mathrm{SH}$ well before the start of the austral winter. This timing coincides with the earliest monsoon onset over the $\mathrm{NH}$ monsoon regions in Central America, Africa and Asia. By mid-July, the rainy season establishes over every NH monsoon region, with a full retreat by October (Fig. 3a, c).

The RegCM4 ensemble mean generally captures the latitudinal transition of the global monsoons. The most notable bias is found over South America, where parts of the Amazon exhibit onset dates later than observed, and over parts of South Asia, Southern Africa and Sahel where the RegCM4 ensemble exhibits an earlier onset than the observed. In addition, the RegCM4 ensemble mean displays a later than observed demise over parts of Australia and South Asia and an earlier than observed demise over parts of South and Central America (Fig. 3). Nonetheless, the RegCM4 simulations exhibit a reasonable overall skill in representing the characteristics of the monsoon during the boreal and austral summers. Moreover, the observed

\section{Monsoon Onset and Demise 1995 to 2014)}

Monsoon Onset
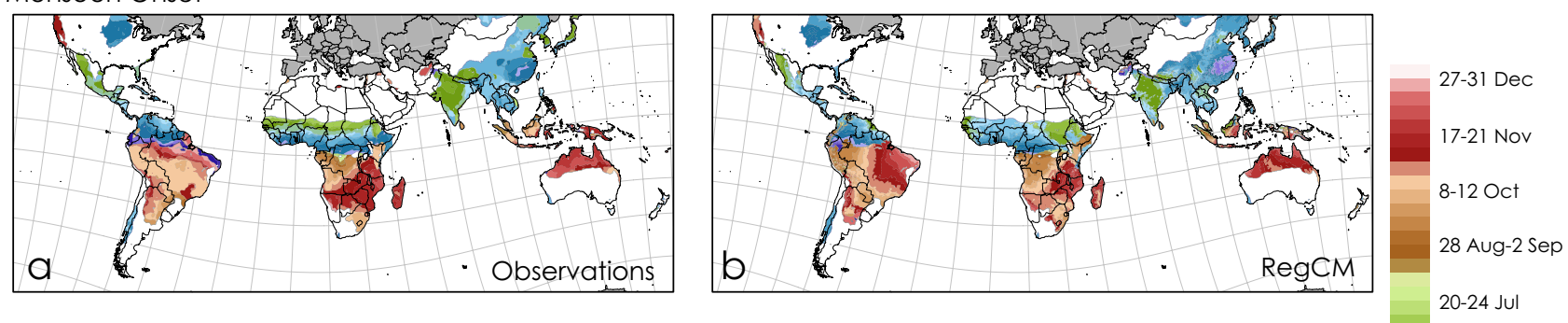

Monsoon Demise
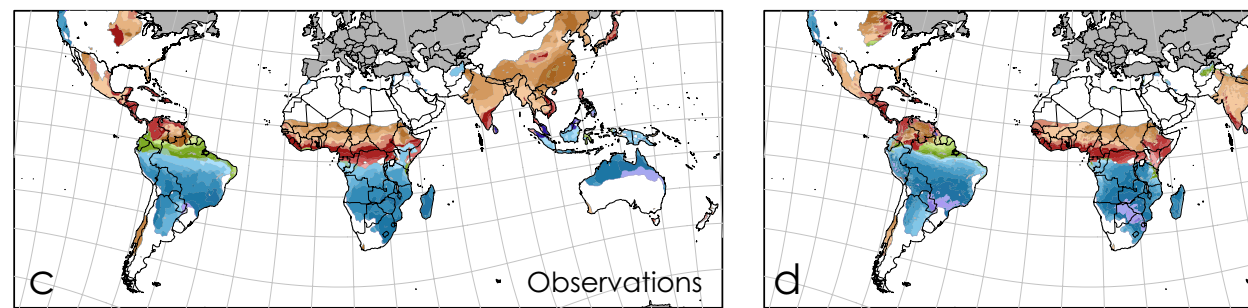

10-14 Jun

-5 May

22-26 Mar

10-14 Feb

1-5 Jan

Fig. 3 Monsoon onset and demise over land in the reference period (1995-2014) in the GPCP Observations (a, c), and the RegCM ensemble (b, d). White land areas are masked where observed seasonality is $<0.025$. Results are not meaningful outside the monsoon regions 
and simulated onset and demise dates using GPCP and RegCM4 regional ensembles are within the uncertainties of other datasets based on similar methodologies (Bombardi and Carvalho 2009).

\subsection{Future changes in the monsoon regions}

Figure 4 shows mid-century (2041-2060) changes in the monsoon metrics shown in Fig. 2. With the exception of a few parts of East Asia and West Africa, the RCP2.6 ensemble exhibits very small changes in seasonality (Fig. 4a). On the other hand, the RCP8.5 ensemble exhibits enhanced seasonality over a few regions, such as the Western Amazon, Eastern Sahel, parts of Central Africa, the Himalayas, and parts of East Asia. This enhancement is greater than the baseline variability over parts of Africa and the Amazon (Fig. 4b). The increase in seasonality is mostly driven by an increase in relative entropy, which exhibits a robust increase (> reference period variability) over parts of Sahel in both scenarios, and over parts of South America and Central Southern Africa (Kalahari Desert and neighboring countries) in the RCP8.5 (Fig. 4c, d). A higher fraction of annual

Near-term Future (2041 to 2060) Changes w.r.t. 1995 to 2014

Seasonality

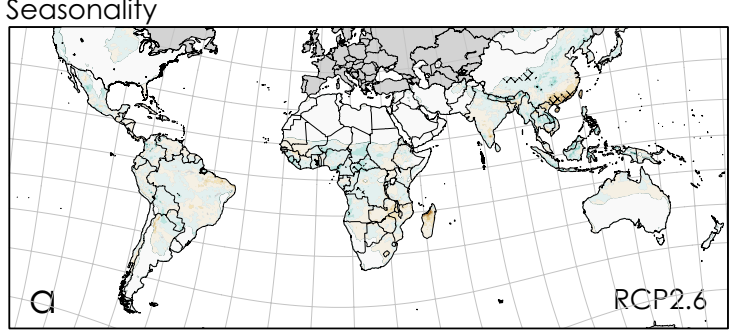

Entropy

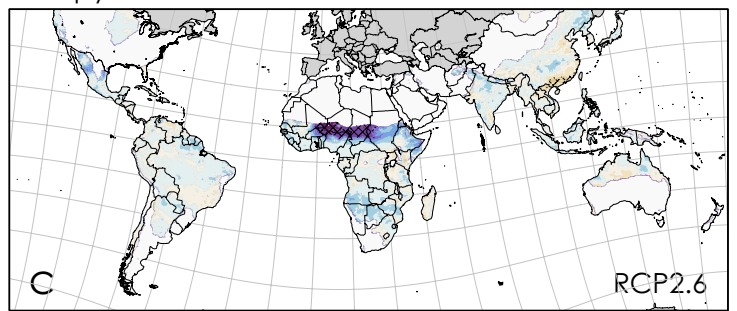

Timing of Centroid

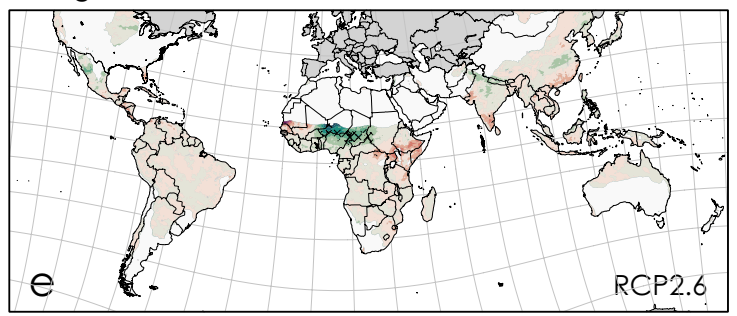

Precipitaion during Peak Season

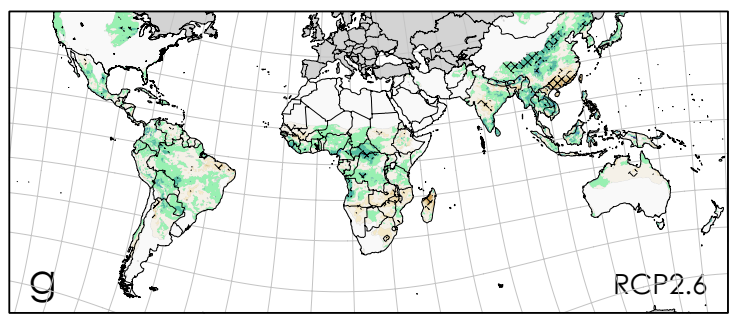

Fig. 4 Simulated projected changes in the near-term future (20412060) with respect to the 1995-2014 period under RCP2.6 and RCP8.5. Seasonality (a, b), entropy (c, d), timing of centroid (e, f), peak season precipitation $(\mathbf{g}, \mathbf{h})$. Stippling represents those regions
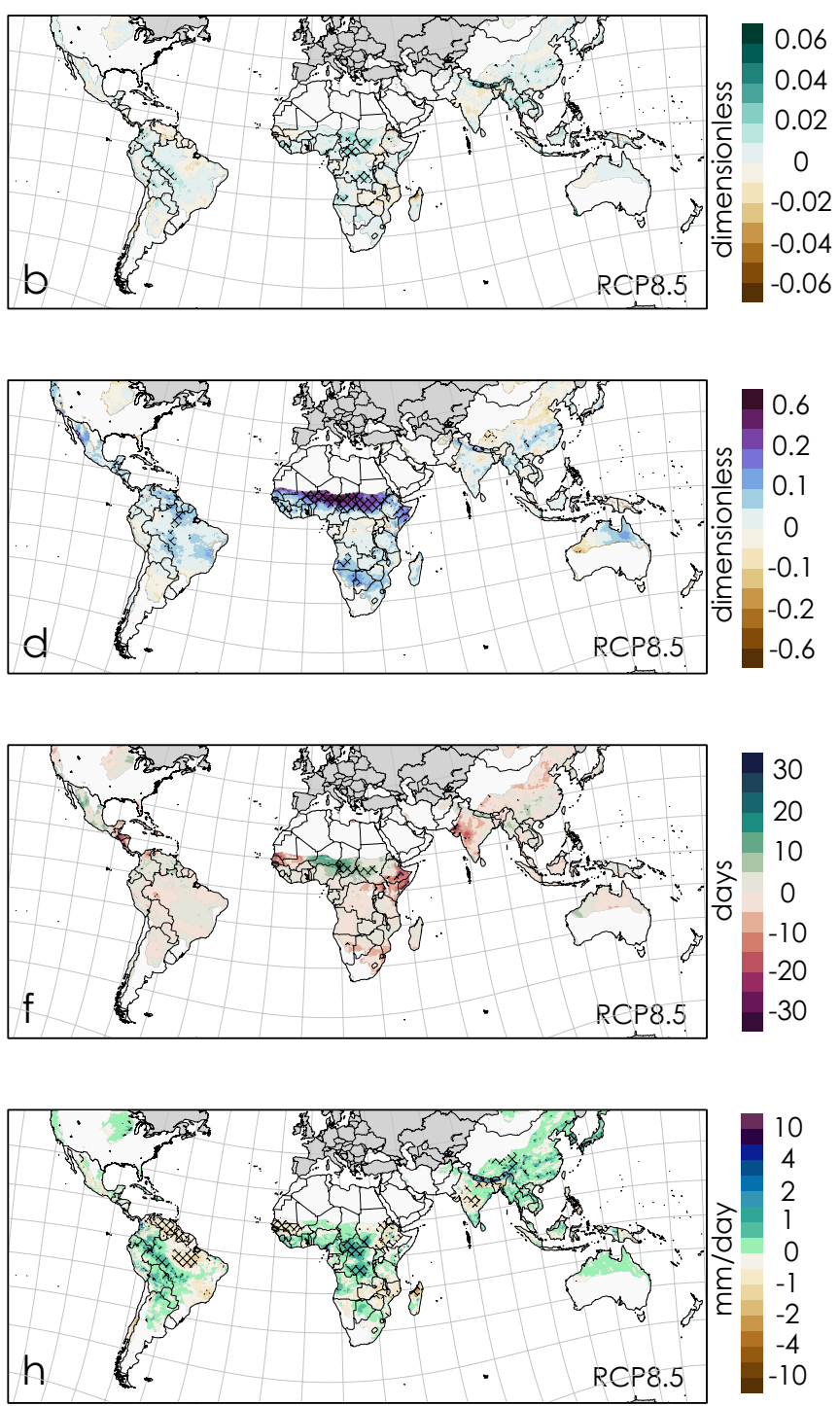

where projected changes are greater than the reference period variability. White land areas are masked where observed seasonality is $<0.025$ 
precipitation during the rainy season (i.e. an increase in relative entropy) results in a forward shift in the timing of the centroid (up to 15 days later than in the reference period) over some regions (Fig. 4e, f).

Most of the monsoon regions show increased precipitation (1-2 $\mathrm{mm} /$ day) during the peak season in both scenarios with exceptions in parts of the Amazon, West Africa and South Asia under the RCP8.5 scenario. Changes over East Asia are generally robust in the RCP2.6 scenario, while changes in the other monsoon regions are greater than the baseline variability only in the RCP8.5 scenario (Fig. 4d, h). We also note an earlier timing of centroid over the regions where monsoon precipitation decreases, e.g. over parts of South Asia, West Sahel and East Africa (Fig. 4e, f).

Stabilization of radiative forcing during the latter half of the twenty-first century in the RCP2.6 results in no major changes in the late-century (2080-2099) monsoon characteristics when compared to those in the mid-century (left columns in Figs. 4, 5), with the exception of parts of the Australian monsoon where precipitation exhibits a robust decrease in the late-century (Fig. $5 \mathrm{~g}$ ). In contrast, in the RCP8.5 ensemble, changes in the monsoon characteristics exhibit similar patterns of change but substantially strong magnitudes in the late-century relative to the mid-century (right columns in Figs. 4, 5). For instance, changes in seasonality become robust over most of the South America, West Africa, and Southeast Asia monsoon areas. Similarly, increases in the relative entropy are robust over monsoon regions in Africa and South America. Likewise, magnitudes of precipitation change nearly double everywhere (>3 mm per day) during the peak season, which includes robust decreases over the West Sahel and Gulf of Guinea in West Africa, Southeast Africa, South Asia, North America and the Eastern Amazon, and robust increases over Central Africa, the Western Amazon, and parts of Southeast Asia, East Asia, Eastern Sahel and Northern Australia (Figs. 4h, 5h). With the exception of Australia, changes in the timing of centroid also exhibit shifts similar to the mid-century period but nearly double in magnitude (up to 30 days).

We note a robust tendency towards a late arrival of monsoons in response to an increase in GHG forcing, as illustrated by a late arrival of the earliest onset everywhere, except over parts of the East and Southeast Asian and North American monsoon regions (Figs. 6a-d, 9, 10). This shift in the start of the rainy season is progressive as higher GHG forcing levels result in further delays. The delay in the timing of the onset is visible in both future scenarios; however, it is spatially more robust in the RCP8.5, which exhibits magnitudes $>3$ pentad shifts over most areas by the midcentury and $>6$ pentads by the late century. The strongest delays in the start of the rainy season are found over the Sahel and parts of South Asia (>8 pentads). A spatially robust delay in the monsoon demise is also exhibited over
South Asia and West Africa in the RCP8.5 in both time periods ( 3 to 5 pentads), however, other regions show mixed responses (Fig. 6e-h). For instance, a later demise of the North American monsoon only becomes spatially robust in the late century under the RCP8.5. Similarly, some areas over the Northern Amazon in South America and Australia (Southeast Asia and South Africa) that exhibit a delayed (earlier) demise during the mid-century period shift to an earlier (delayed) demise in the late century period. Nonetheless, we can conclude that monsoon regions in general exhibit a prevailing shrinking of the monsoon season as the delays in the monsoon onset, in most cases, are more pronounced than the delays in the monsoon demise.

\section{Discussion}

\subsection{Drivers of projected changes in regional monsoons}

A holistic review of intra-annual land-atmospheric characteristics is required to identify the drivers of projected changes in regional monsoons. Complex land-atmospheric processes prepare a monsoon region for the transition to the rainy season while the ITCZ inter-hemispherically oscillates towards warmer continents. Several months before the start of the rainy season (pre pre-monsoon), each monsoon region exhibits a stable atmosphere and dry conditions (Figs. 7, 8; first column), with deep atmospheric subsidence in the zonally averaged wind vectors of divergence and vertical velocity, and low magnitudes of zonally averaged precipitation (Figs. 9 and 10). Around the time of monsoon demise in one hemisphere, land begins to warm in the other, which initiates shallow overturning in the lower troposphere (Figs. 7, 8; second column) through sensible heating. During that time, surface temperatures reach the annual maximum, which drives the development of heat lows before the monsoon onset. Every monsoon region receives a noticeable amount of premonsoon precipitation (Figs. 11a), which helps to warm up the upper troposphere (Fig. 12) and induce deep overturning through latent heat release in the atmosphere (Figs. 7, 8; third column). Pre-monsoon diabatic heating thus prepares the region to transition into a highly conducive regime for atmospheric convection during the monsoon onset.

The latent heat, driven by atmospheric warming from the pre-monsoon to the monsoon phase, can be explained through the monthly anomalies of zonally averaged uppertropospheric (500-200 mb) temperatures with respect to annual means (Figs. 12, 13; first column). These figures demonstrate the meridional differential heating in the upper troposphere that is responsible for large-scale atmospheric shear during the monsoon season and precipitation progression along the summer hemisphere latitudes (Held 


\section{Long-term Future (2080 to 2099) Changes w.r.t. 1995 to 2014}

Seasonality

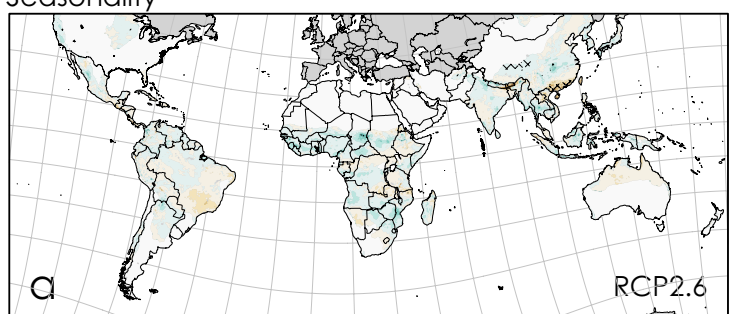

Entropy

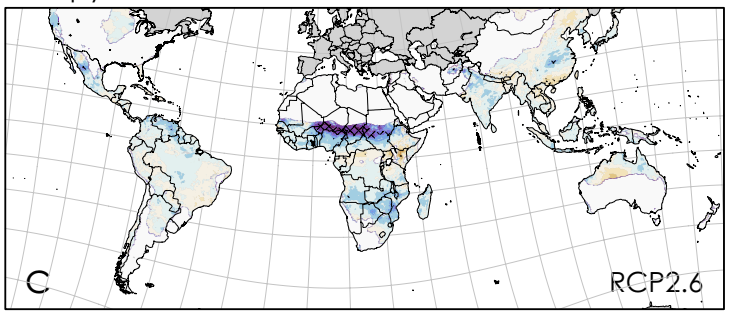

Timing of Centroid

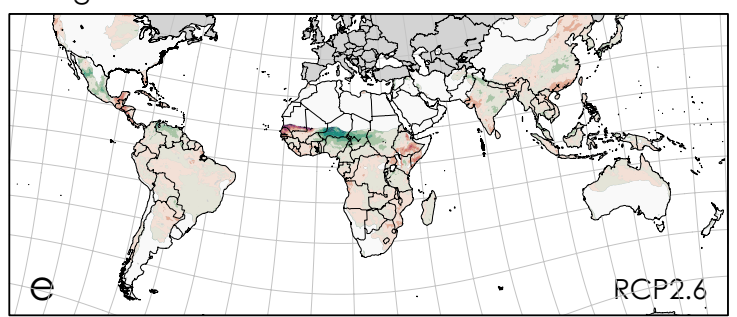

Precipitation during Peak Season

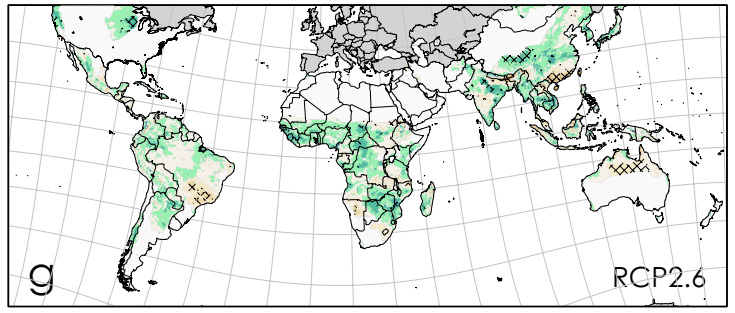

Fig. 5 Simulated projected changes in the far future (2080-2099) with respect to the 1995-2014 period under RCP2.6 and RCP8.5. Seasonality $(\mathbf{a}, \mathbf{b})$, entropy $(\mathbf{c}, \mathbf{d})$, timing of centroid $(\mathbf{e}, \mathbf{f})$, peak sea-

and Hou 1980; Lindzen and Hou 1988). Zonally averaged upper tropospheric temperatures over each monsoon region reaches higher than the annual mean before the earliest monsoon onset (Figs. 12, 13; first column, zero-line contours). Intense latent heating of the atmosphere during the monsoon is reached at the peak of the season, which coincides with the maxima of seasonal precipitation (Figs. 9, 10; first column), meridional differential heating (Figs. 12, 13; first columns), and deep vertical ascending motion (Figs. 7, 8; third column). We note that the inter-seasonal overturning of atmospheric circulations (Figs. 7, 8; last three columns), the distribution of pre-monsoon precipitation (Figs. 9, 10;
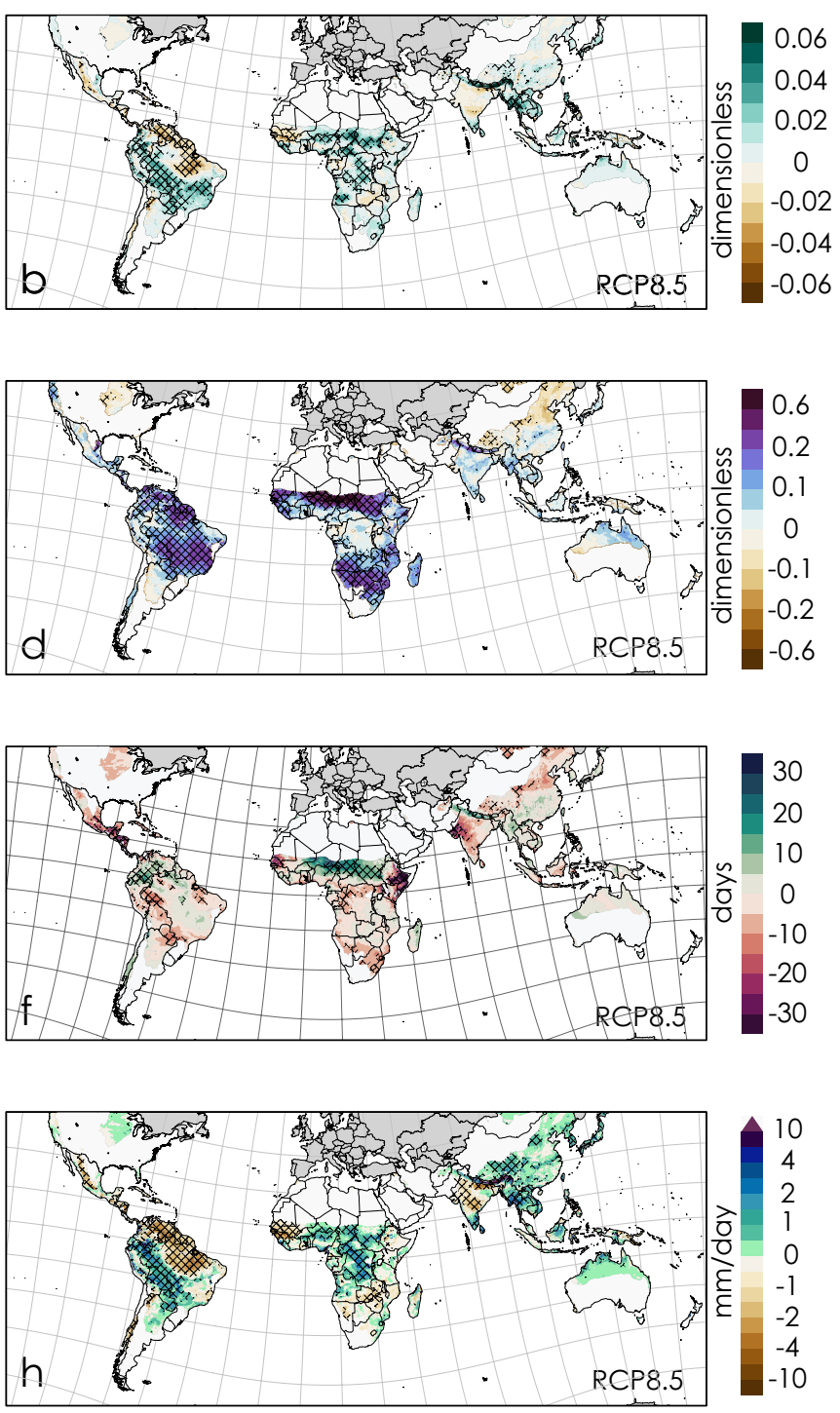

son precipitation $(\mathbf{g}, \mathbf{h})$. Stippling represents those regions where projected changes are greater than the reference period variability. White land areas are masked where observed seasonality is $<0.025$

second column) and the meridional differential heating (Figs. 12, 13; second column) are represented quite well in the RegCM4 ensemble over each monsoon region. The most noticeable systematic biases occur over South and East Asia, and South America, where the model exhibits weaker monsoon circulations, which in turn explain the dry biases over parts of these regions.

Given the progressive nature of simulated changes in regional monsoon characteristics as a function of GHG forcing (Figs. 4, 5, 6), we restrict our focus only to the late twenty-first century changes under the RCP8.5 scenario to highlight the potential mechanisms responsible for the 


\section{Future Changes w.r.t. 1995 to 2014}
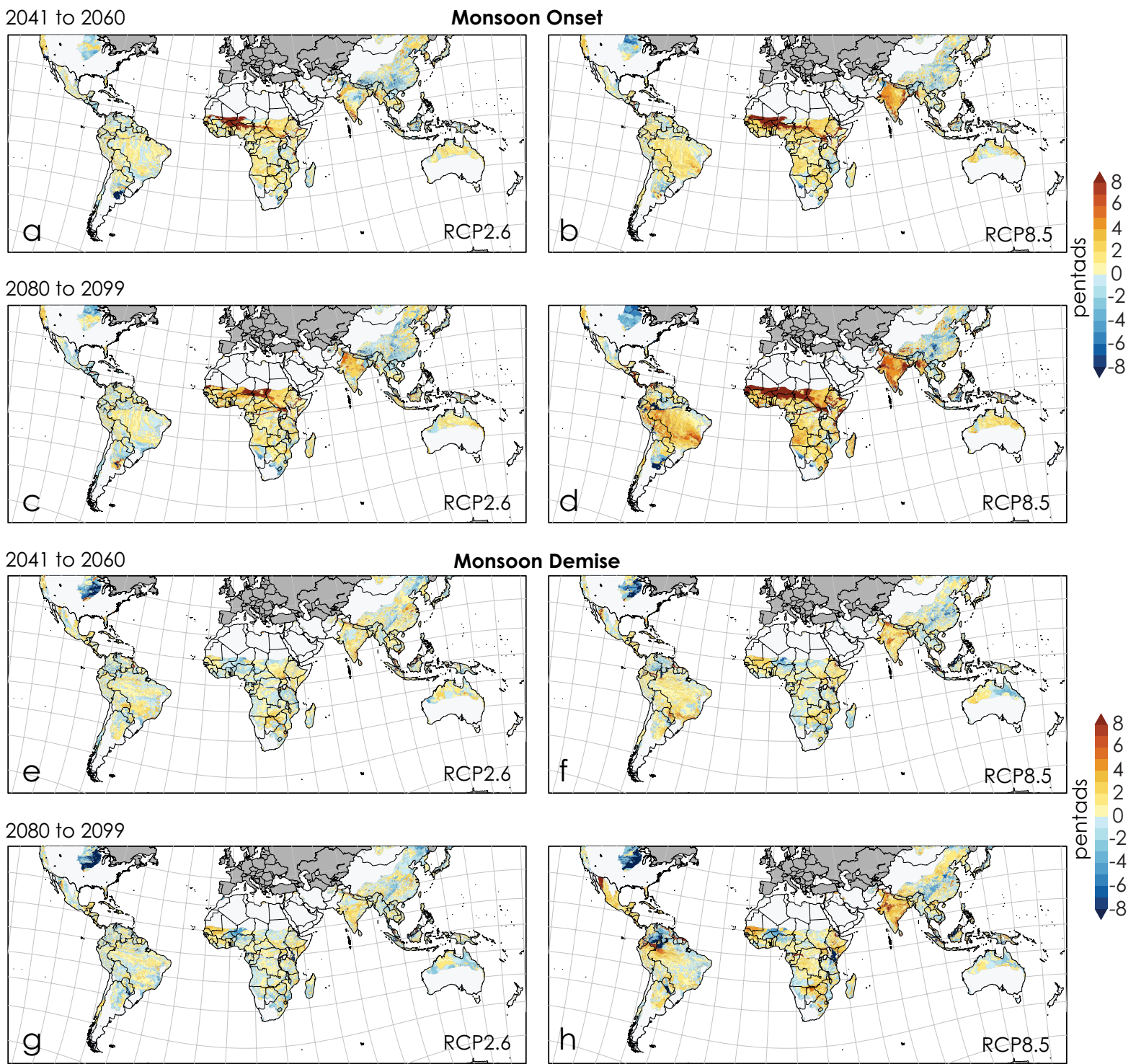

Fig. 6 Simulated projected changes in the monsoon onset (a-d) and demise (e-h) in the RCP2.6 (left column) and the RCP8.5 (right column). Changes are shown for the near-term (2041-2060) and the

long-term (2080-2099) with respect to 1995-2014. White land areas are masked where observed seasonality is $<0.025$. Results are not meaningful outside the monsoon regions

projected variations in monsoon onset and precipitation characteristics. Because the magnitudes of changes are highest during the late twenty-first century period under RCP8.5 (Figs. 5, 6), we expect that clear causal connections can be established between precipitation responses and variations in the underlying physical processes.

The projected delay in the monsoon onset is deeply rooted in pre-monsoon precipitation dynamics. With the exception of East and Southeast Asia, the two regions where the monsoon onset does not exhibit a spatially robust delay, changes in zonally averaged precipitation exhibit a decrease in every region (Figs. 9, 10; right two columns). Spatially, this pre-monsoon decrease corresponds very well with the changes in monsoon onset (Figs. 6d, 11d). The observed pre-monsoon precipitation is mostly convective in nature over the monsoon regions, in contrast to the mature monsoon season where the fraction of stratiform precipitation also increases due to the presence of organized precipitation systems (Schumacher and Houze 2003). The predominance of convective precipitation during the pre-monsoon season also occurs in our simulations, given the remarkable resemblance between the simulated future changes in the pre-monsoon total and convective precipitation (Fig. 11c-f). We note that those monsoon regions where convective precipitation is 


\section{Divergence $\left(\times 10^{6}\right.$ ) and Vertical Velocity ( $\left.\times 50\right)$ Vectors with Vertical Velocity ( $\times 50$ ) as Colored Contours}

ERA5

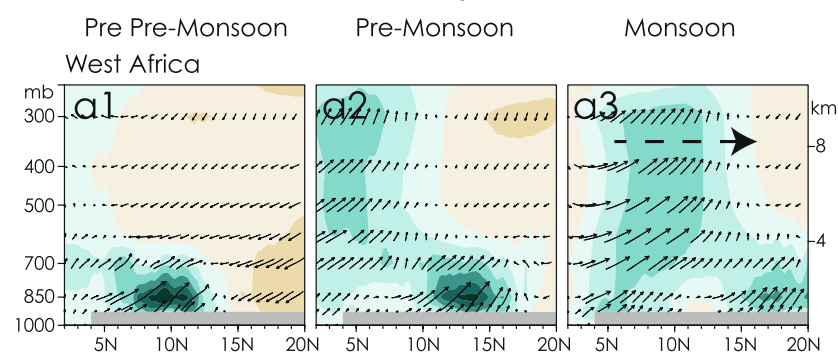

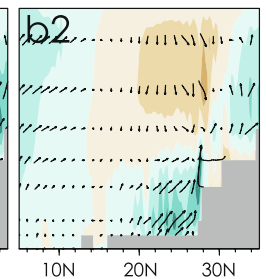

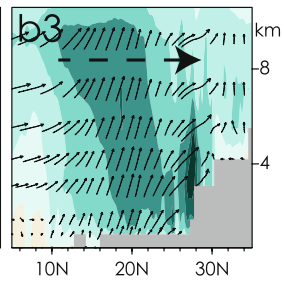

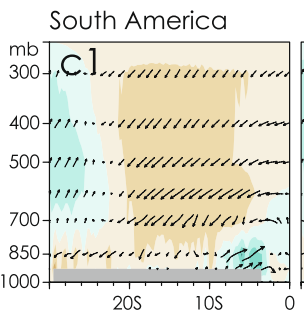
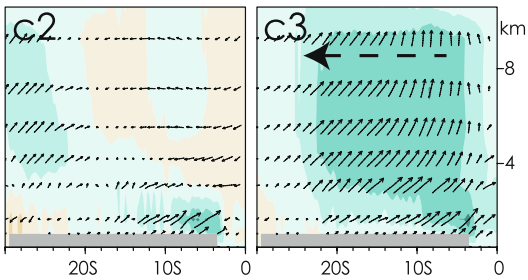

Southeast Africa
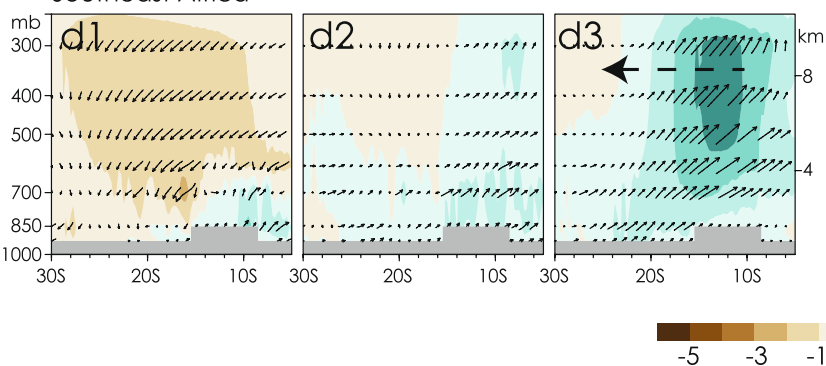

Fig. 7 Latitude-height cross-section of divergence (1/s) and vertical pressure velocity $(\mathrm{Pa} / \mathrm{s})$ in ERA5 (left three columns) and RegCM (right three columns), shown as wind vectors averaged over West Africa (a1-a6; 15 W-15 E, 2-20 N), South Asia (b1-b6; 70-95 E, 5-35 N), South America (c1-c6; 60-40 W, 0-30 S), and Southeast Africa (d1-d6; 15-45 E, 5-30 S). Colored contours represent vertical pressure velocity. Black arrows represent the direction of the monsoon along the latitude. Both vertical pressure velocity and diver-

suppressed during the pre-monsoon also exhibit an increase in the height, or depth, of the atmospheric boundary layer and a decrease in relative humidity, or the saturation level, in the lower troposphere (Fig. 12). In present climate conditions, the convective environments over the monsoon regions during the pre-monsoon exhibit a sharp contrast from their

\section{RegCM Ensemble}
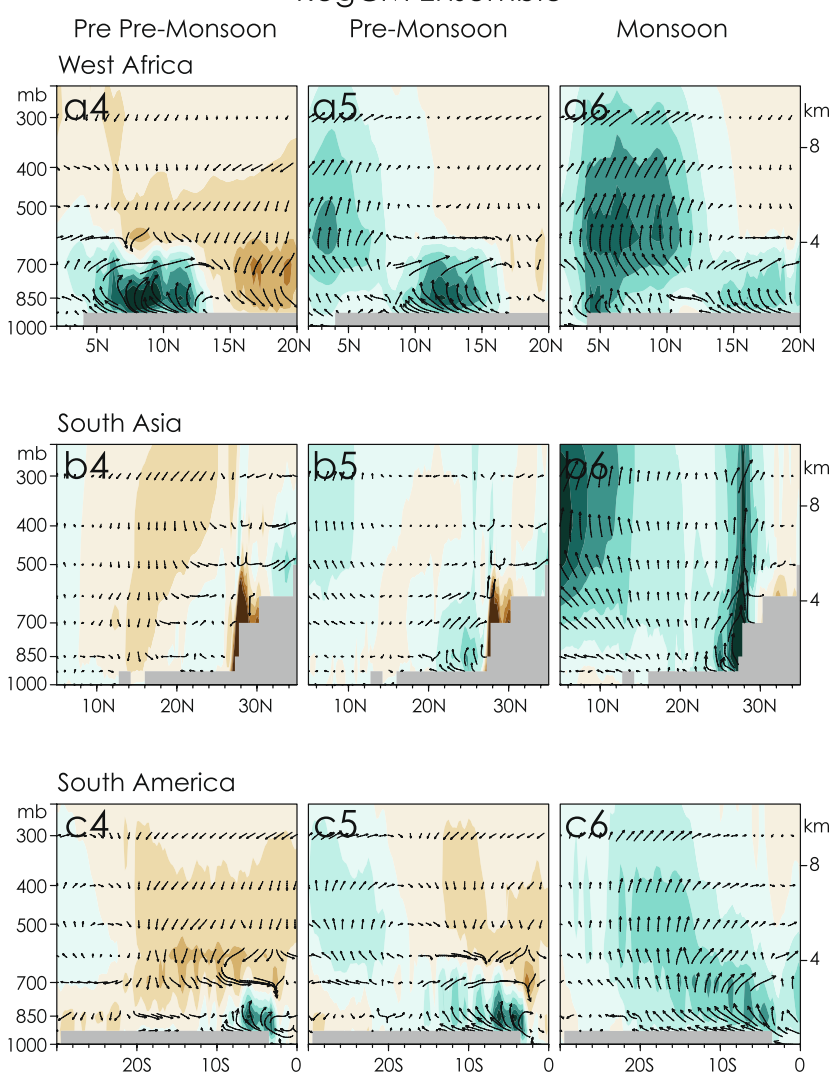

Southeast Africa
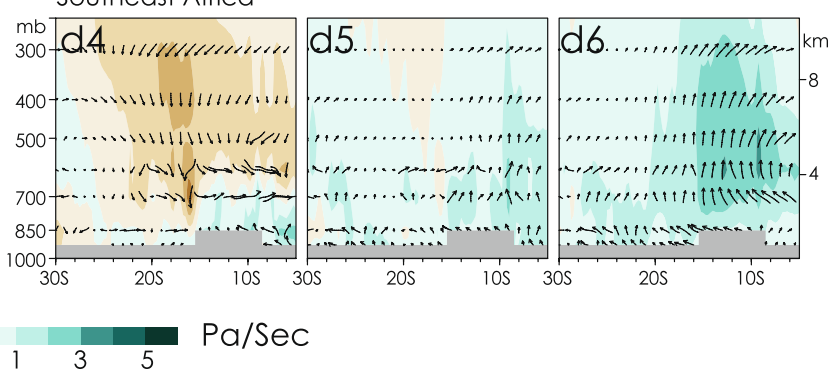

gence have been exaggerated by 50 and $10^{6}$ in all plots. Vertical pressure velocity is multiplied by -1 so that positive values represent an upward motion. The three panels in each case represent averages over pre pre-monsoon, pre-monsoon and monsoon periods. The Pre-monsoon period represents the average over the two months prior to the monsoon season. The pre pre-monsoon period represents the average over two months prior to the pre-monsoon period

respective monsoon seasons, with a relatively deeper atmospheric boundary layer, highly variable atmospheric moisture and a predominant thermally driven convection due to warmer land surface and limited soil moisture conditions (Thomas et al. 2018). Two potentially unfavorable developments in the pre-monsoon convective environments take 
Divergence $\left(\times 10^{6}\right.$ ) and Vertical Velocity ( $x 50$ ) Vectors with Vertical Velocity ( $x 50$ ) as Colored Contours

\section{ERA5}
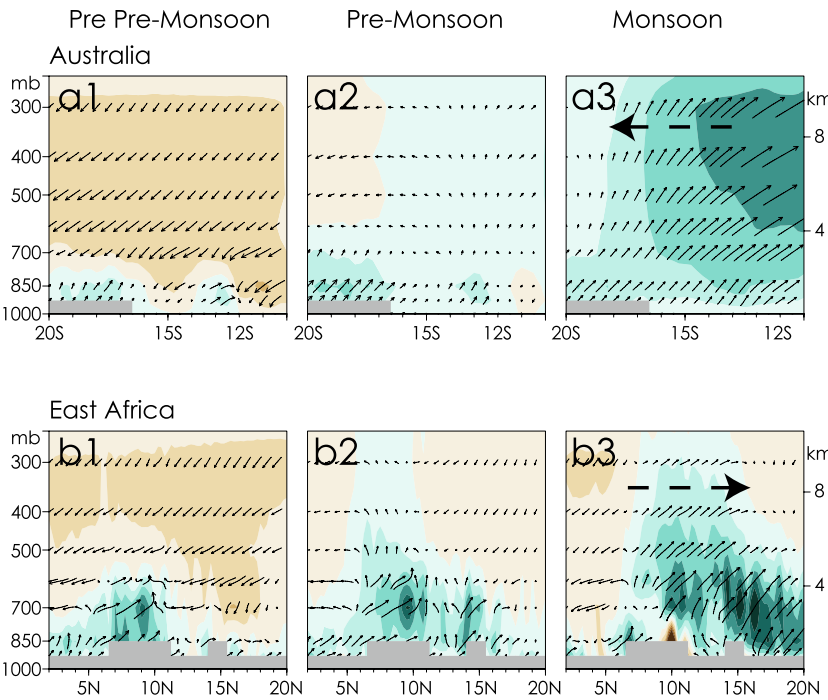
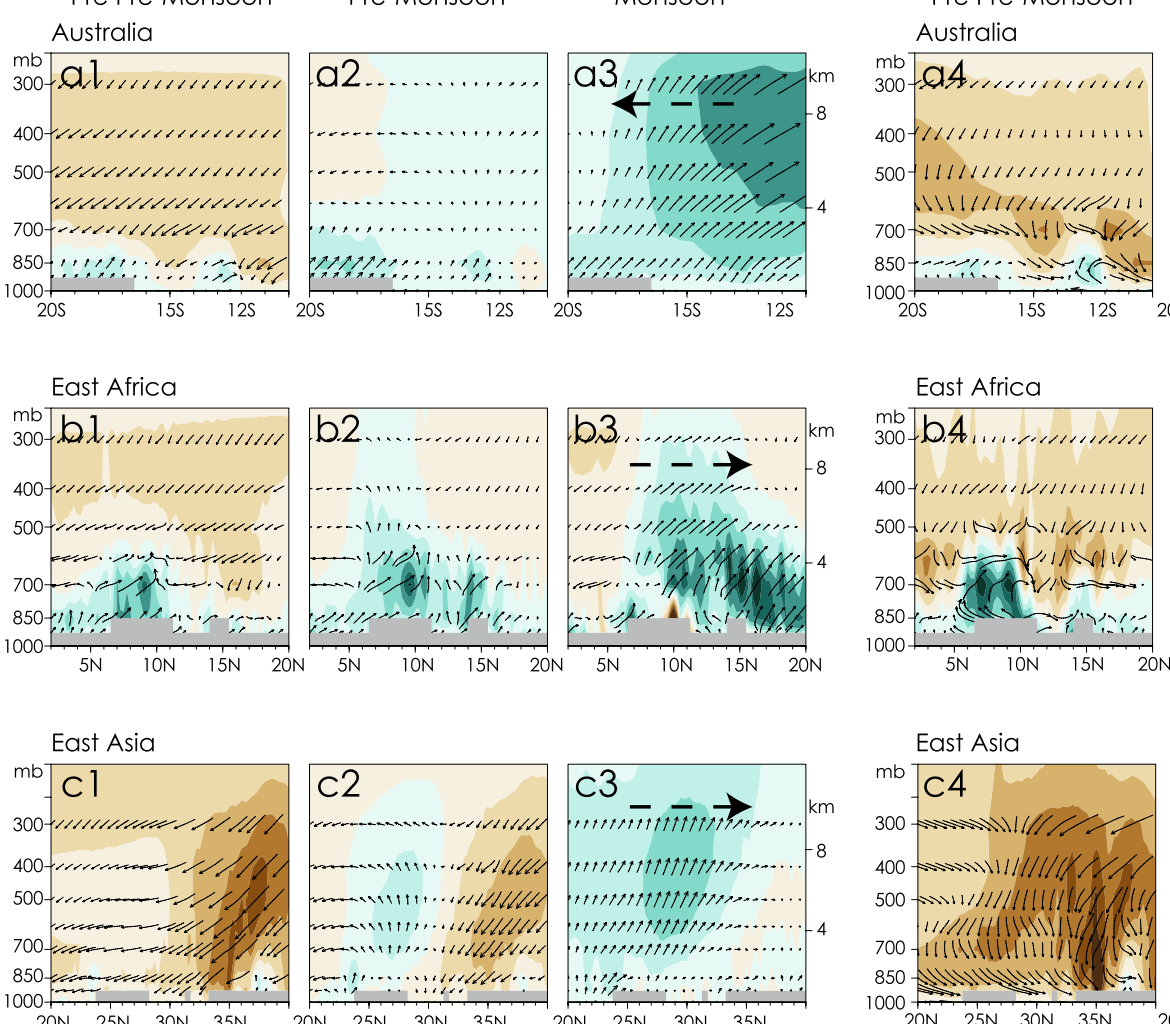

RegCM Ensemble

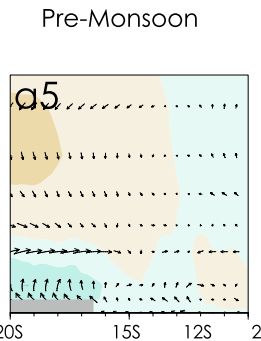

Monsoon
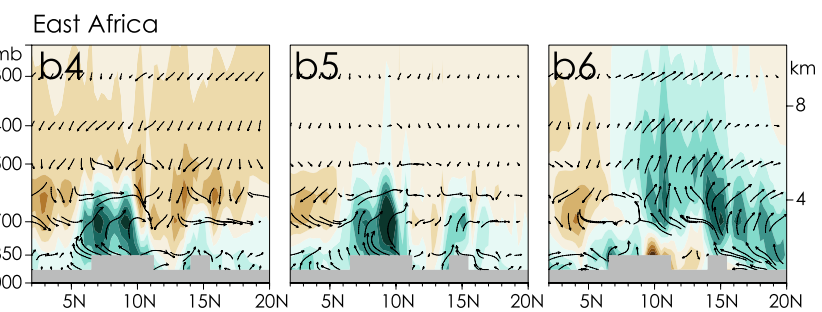

$20 \mathrm{~N} \quad 25 \mathrm{~N} \quad 30 \mathrm{~N} 35 \mathrm{~N}$

$20 \mathrm{~N} \quad 25 \mathrm{~N} \quad 30 \mathrm{~N} 35 \mathrm{~N}$

Southeast Asia
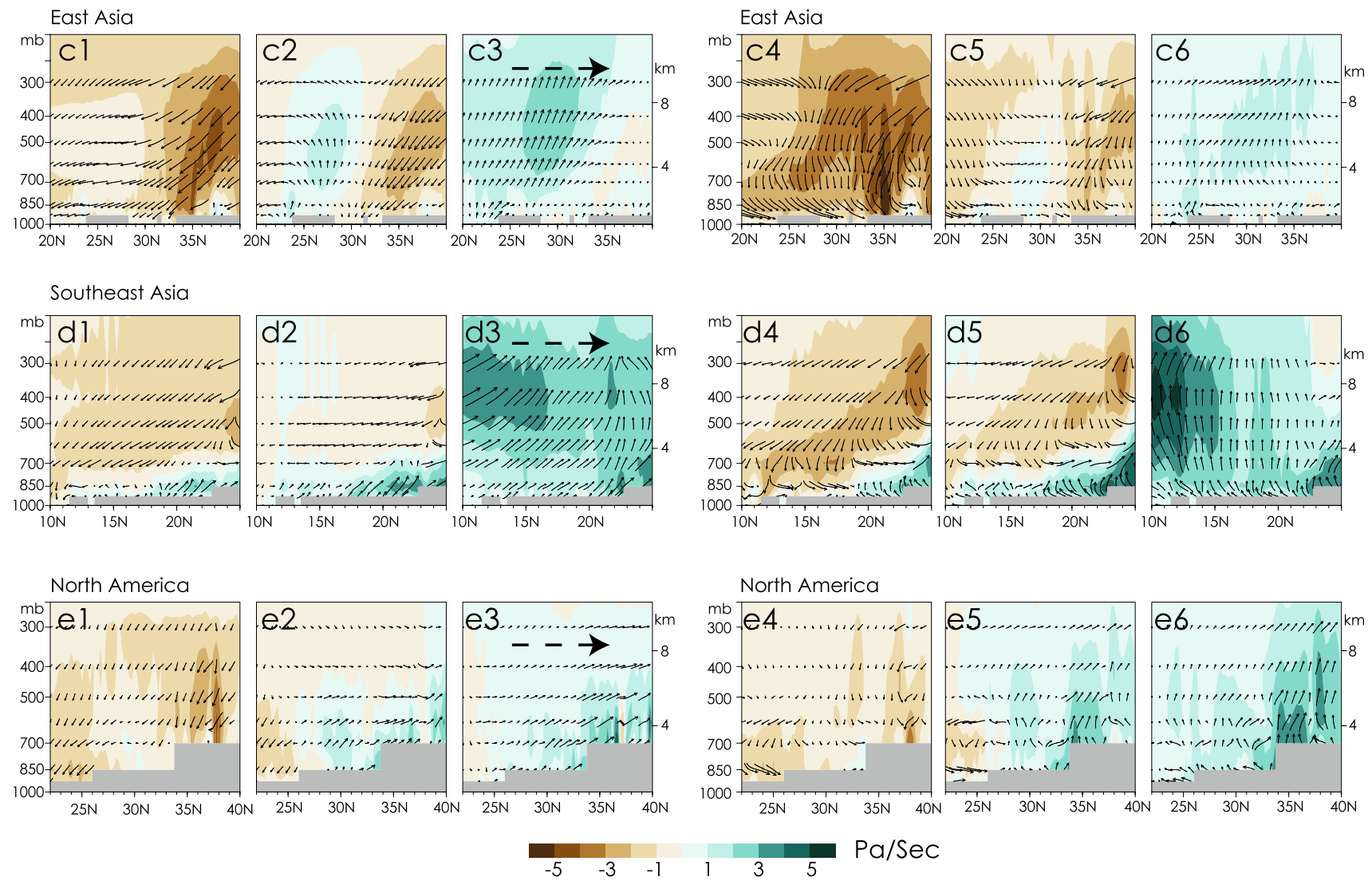

$\mathrm{Pa} / \mathrm{SeC}$

Fig. 8 Same as in Fig. 7 but over Australia (a1-a6; 130-150 E, 10-20 S), East Africa (b1-b6; 32-50 E, 2-20 N), East Asia (c1-c6; 110-140 E, 20-40 N), Southeast Asia (d1-d6; 95-110 E, 10-25 N), and North America (e1-e6; 114-104 W, 22-40 N) 


\section{Zonally Averaged Precipitation over Monsoon Regions}

Reference Period (1995 to 2014)

Changes in w.r.t. 1995 to 2014
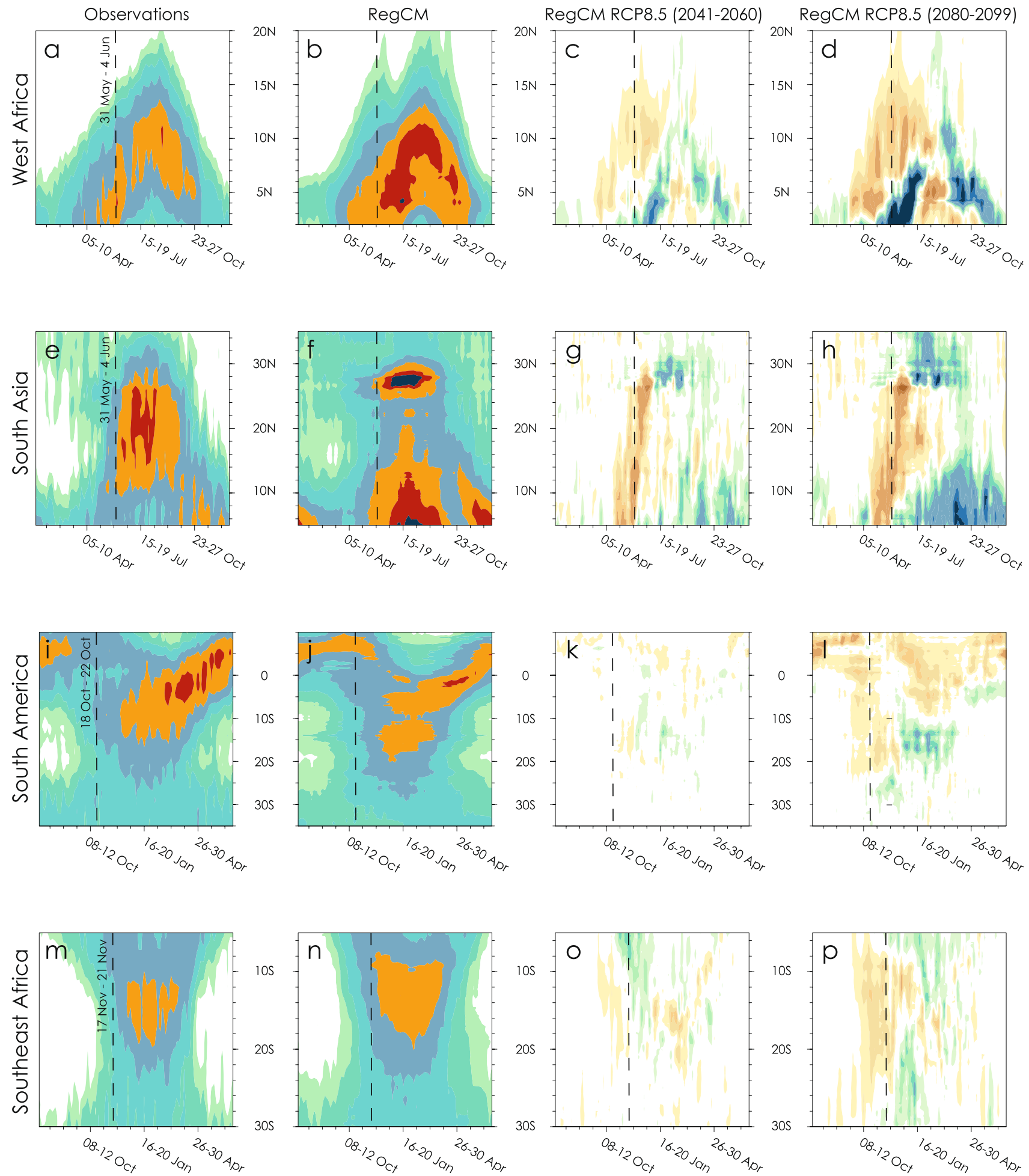

$\begin{array}{lllllllll}0 & 0.5 & 1 & 2 & 4 & 7 & 11 & 15\end{array}$

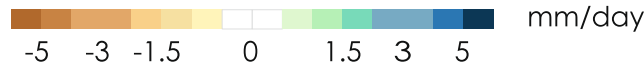


4Fig. 9 Zonally averaged 5-day mean precipitation (1995-2014) in the GPCP observations (first column) and in the RegCM simulations (second column) over West Africa (a, b; 15 W-15 E, 2-20 N), South Asia (e, f; 70-95 E, 5-35 N), South America (i, j; 80-40 W, 10 N-35 S), and Southeast Africa (m, n; 15-45 E, 5-30 S). Mid-term (20412060) and long-term (2080-2099) future changes in zonal average 5-day mean precipitation under RCP8.5. Africa (c, d), South Asia (g, $\mathbf{h})$, South America $(\mathbf{k}, \mathbf{l})$, and South Africa $(\mathbf{o}, \mathbf{p})$. The vertical lines in each panel represent the approximate climatological timing (in pentads) by when the region receives earliest monsoon precipitation in the observations as shown in Fig. 3

place in the future climate conditions. First, as the land surface warms in response to future increases in radiative forcing, the atmospheric boundary layer grows even deeper due to a greater partitioning of the surface energy flux towards sensible heating. A deeper atmospheric boundary layer requires an additional buoyancy force to lift air parcels to their level of free convection. Second, future warming of the overlying atmosphere increases the required amount of moisture needed for the atmospheric boundary layer to become convectively unstable (Chou and Neelin 2004; Langenbrunner et al. 2019). While the atmosphere is expected to be more moist in future climates, the additional moisture requirement for convective initiation is challenging to satisfy during the pre-monsoon due to the limited moisture supply as winds predominantly blow from the dry land regions - an upped-ante mechanism that leads to reduced precipitation (Chou and Neelin 2004; Neelin et al. 2003). Neelin et al. (2003) suggest that warming induced by the increase in greenhouse gas forcing raises the amount of moist static energy requirements for convective instability in the atmospheric boundary layer, which is analogous to the game of poker where stakes get higher when a player ups the ante. This additional moisture requirement is difficult to fulfill in subsidence zones where atmospheric flow in the lower levels is from non-precipitating regions. Overall, these unfavorable developments in the future period increase atmospheric stability and reduce convective precipitation during the premonsoon months (Figs. 11, 12).

Below normal pre-monsoon precipitation in the future period drives a potential decrease in tropospheric latent heat release, which is displayed by a shift in the warming pattern of the upper troposphere in the future period (Figs. 13, 14; right column). The lack of latent heat driven diabatic heating delays the deep overturning of atmospheric subsidence during the pre-monsoon phase, particularly over West, East and Southeast Africa, South Asia and South America, which exhibit strong delays in the monsoon onset (Fig. 15). It should be noted that each of these regions exhibit a strengthening of shallow overturning in the lower atmosphere over land (Fig. 15; positive values in the lower atmospheric levels), which is indicative of an increase in sensible heating due to warmer surface temperatures in the future period.
However, increases in sensible heating alone are unable to compensate the diabatic heating deficit in the upper troposphere, which are caused by decreased pre-monsoon precipitation. Similar mechanisms have been shown to cause a delayed onset bias over South Asia in the CMIP5 GCMs (Ashfaq et al. 2017). Such an anomalous deep subsidence is not visible over East and Southeast Asia, and North America due to the lack of a clear spatial pattern of a delay in the monsoon onset (Figs. 4d, 15). On the other hand, an increase in pre-monsoon precipitation may cause a decrease in the strength of sensible heat driven heat lows, which is reflected as an anomalous sinking motion in the lower levels, such as over East and Southeast Asia and East Africa (Fig. 15f1-g1). Weaker than normal precipitation during the monsoon season is reflected in the anomalous subsidence during the monsoon season, which is more prominent over parts of West and Southeast Africa, South Asia and South America (Fig. 15; brown color). A substantial late season warming in the upper troposphere, such as over the North American monsoon region (Fig. 10f), is indicative of a robust delay in the monsoon demise (Fig. 6h).

The delay in monsoon onset and demise are not the only major changes in regional monsoon characteristics. Rainy seasons across the monsoonal belt exhibit shrinking in response to higher levels of GHG forcing. The increase in precipitation over parts of the monsoon regions (Fig. 5g, h) in connection with a shorter length of the rainy season points towards an increase in the intensity of the monsoon rains and a decrease in the fraction of annual precipitation outside of the monsoon seasons (Fig. 5d).

Many of the findings in our analyses are supported by earlier studies over a number of regional monsoons. The late twenty-first century precipitation increases over many areas are consistent with the CMIP5 multi-model analyses (e.g. Hsu et al. 2012; Kitoh et al. 2013). A potential delay in the monsoon onset over South Asia and parts of Africa has been reported previously by high-resolution RCM based studies (Akumaga and Tarhule 2018; Ashfaq et al. 2009; Diallo et al. 2016; Kumi and Abiodun 2018; Mariotti et al. 2014). Similarly, the lack of evaporation, the changes in the atmospheric boundary layer structure and the decrease in moisture convergence are linked to pre-monsoon drying in the future projections of CMIP5 models or in enhanced CO2 experiments (Langenbrunner et al. 2019; Seth et al. 2013). Likewise, earlier studies support a late demise over North America (Colorado-Ruiz et al. 2018; Cook and Seager 2013; Seth et al. 2013), and a decrease in the meridional tropospheric thermal contrast over South Asia and North America (Ashfaq et al. 2009; Mei et al. 2015; Torres-Alavez et al. 2014). Moreover, dipolar latitudinal changes in precipitation over South America (where dry conditions persist north of the Equator and wet conditions to the south) are consistent not only with previous modeling studies using GCMs (Jones 
Zonally Averaged Precipitation over Monsoon Regions
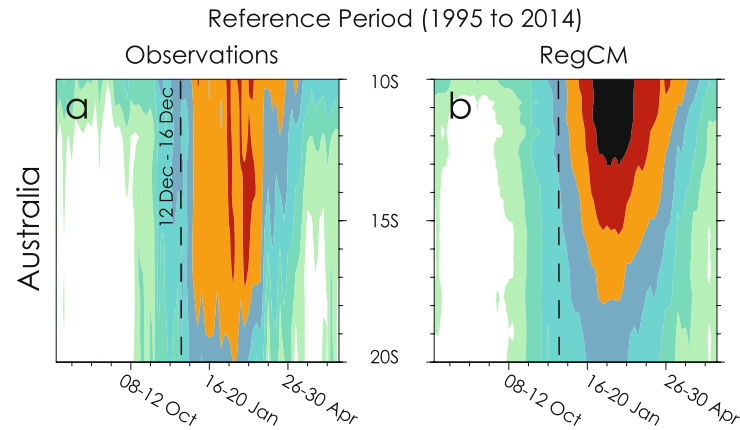

Changes in w.r.t. 1995 to 2014
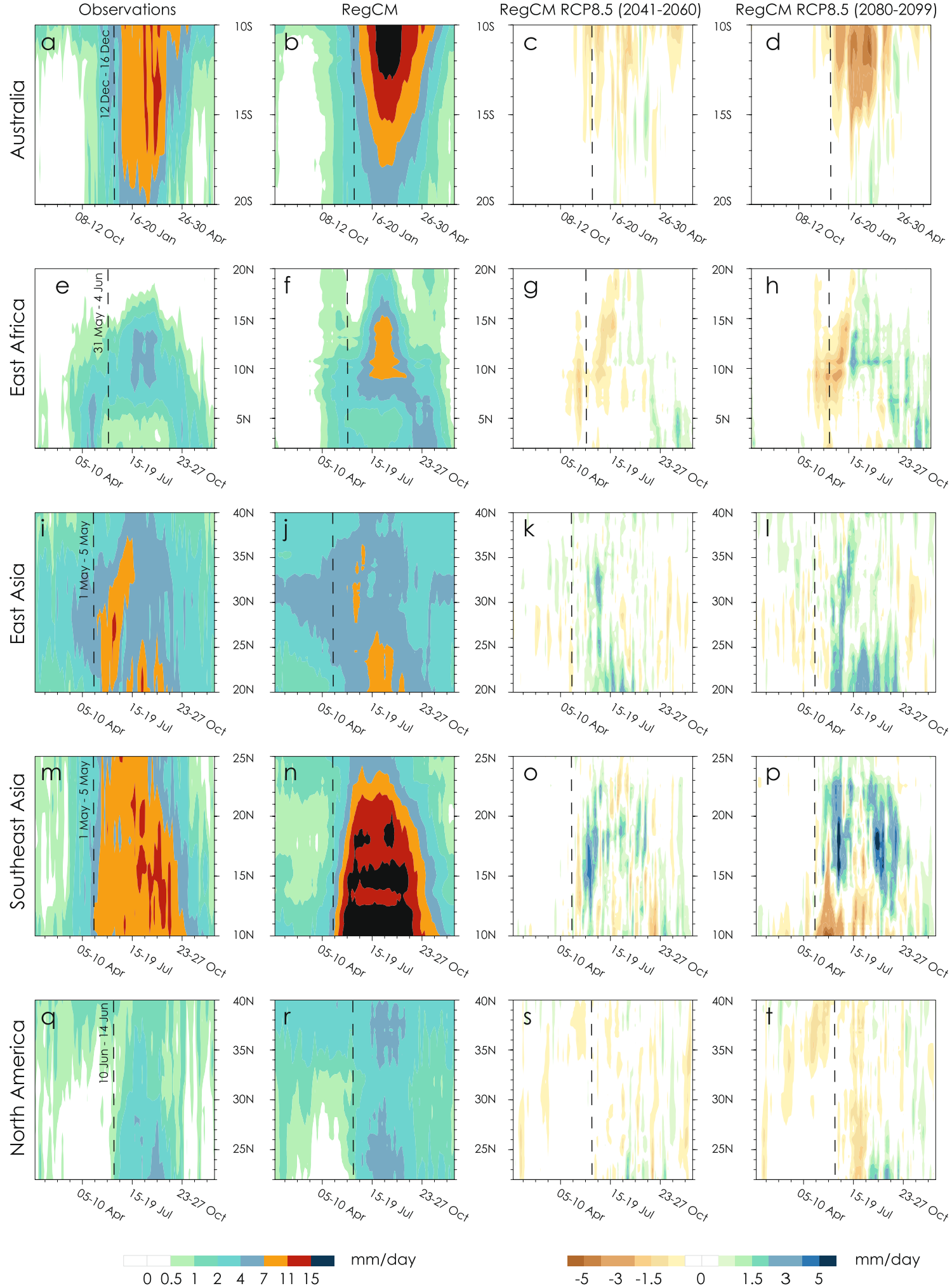

$\mathrm{mm} / \mathrm{day}$

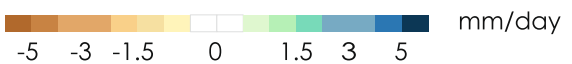

Fig. 10 Same as in Fig. 9 but for Australia (a-d; 130-150 E, 10-20 S), East Africa (e-h; 32-50 E, 2-20 N), East Asia (i-l; $110-140$ E, 20-40 N), Southeast Asia (m-p; 95-110 E, 10-25 N), and North America (q-t; 114-104 W, 22-40 N) 


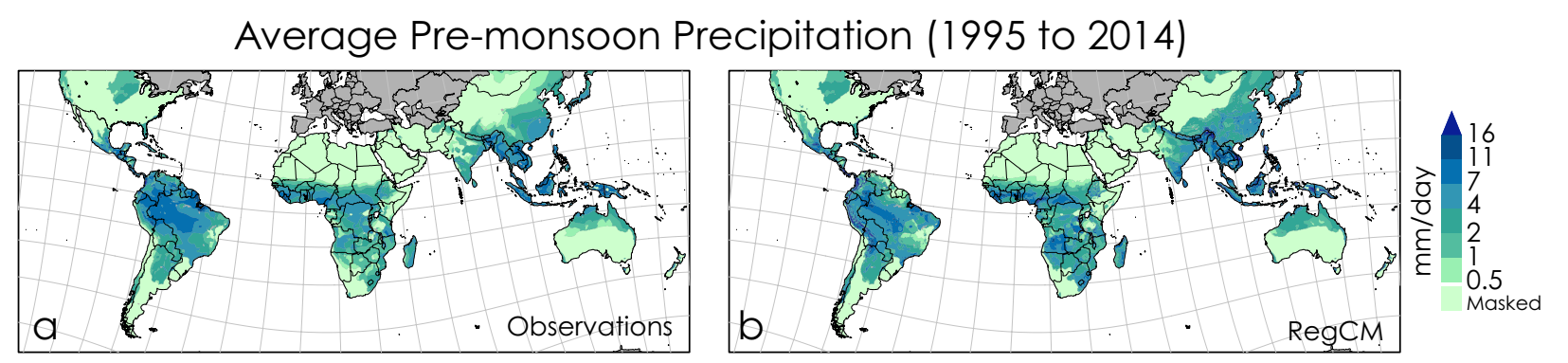

Changes in Average Pre-monsoon Precipitation
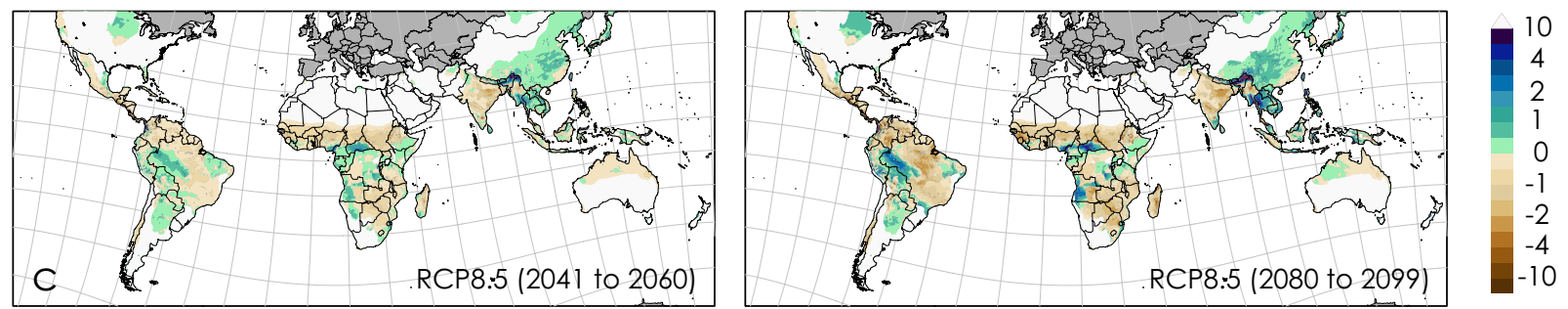

\section{Changes in Average Pre-monsoon Convective Precipitation}
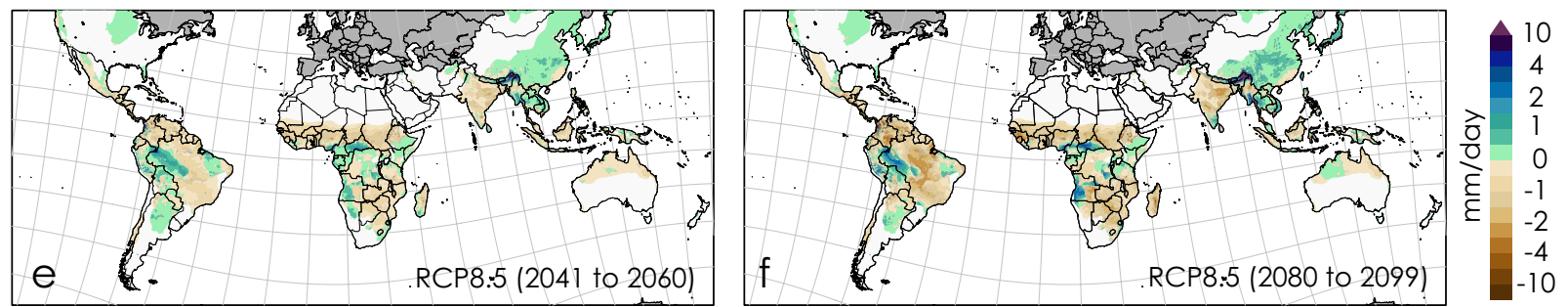

Fig. 11 Pre-monsoon precipitation during 1995-2014 in a CRU observations, b RegCM ensemble. Projected changes w.r.t. 19952014 in the pre-monsoon c, $\mathbf{d}$ total precipitation, and e, $\mathbf{f}$ convec- tive precipitation during c, e 2041-2060 and d, f 2080-2099 under RCP8.5. The pre-monsoon precipitation represents the average of the two months before the peak monsoon season at each grid point and Carvalho 2013) and RCMs (Llopart et al. 2019; Reboita et al. 2014), but also in the observations (Sena et al. 2018).

\subsection{Implications of changes in regional monsoons}

The projected variations in the onset, duration, and demise of the monsoons and the resulting changes in seasonal precipitation have strong implications for regional planning, especially for energy, health, agricultural and water resource sectors. For instance, $75 \%$ of energy production in Brazil is through hydropower, where a projected shift in rainfall timing will have a detrimental impact on the adequacy of energy production during certain times of the year (de Queiroz et al. 2019). Additionally, hydropower is a significant source of energy in India and Pakistan, where significant delays in monsoon onset and decreases in summer precipitation is projected. Similarly, agriculture has a major footprint on the human lives and economies of Asian, African and American monsoon regions. Economic impacts on agricultural production due to monsoon variations in these monsoon regions can be seen throughout the world (Rojas et al. 2019). As an example, over half of the global arabica coffee supply is produced in Brazil and over $70 \%$ of cacao production, the ingredient used to make chocolate, comes from Ghana and the Ivory Coast in West Africa. Both coffee and cacao are highly rain dependent and during times without rain, such as those that occur during a delayed monsoon onset or drought conditions, result in decreased yields and increased prices (de Camargo 2010; Schroth et al. 2016). Likewise, a delay in monsoon onset and/or variations in rainy season precipitation has been a known source of vector borne diseases (e.g. cholera, malaria, dengue) in Africa, South Asia and South America (Benitez 2009; Dash et al. 2013; Dhiman et al. 2010). Extreme weather events are already on the rise in many countries across the monsoon belt (Zhang and Zhou 2019). A shrinking of the rainy season and strong wet and dry projected variations in precipitation are indicative of further strengthening of the prevailing trends under enhanced GHG forcing, which may push highly vulnerable socioecological systems in the monsoon impacted developing world beyond their elasticity. 
Zonally Averaged Pre-monsoon Relative Humidity and Atmospheric Boundary Layer Height
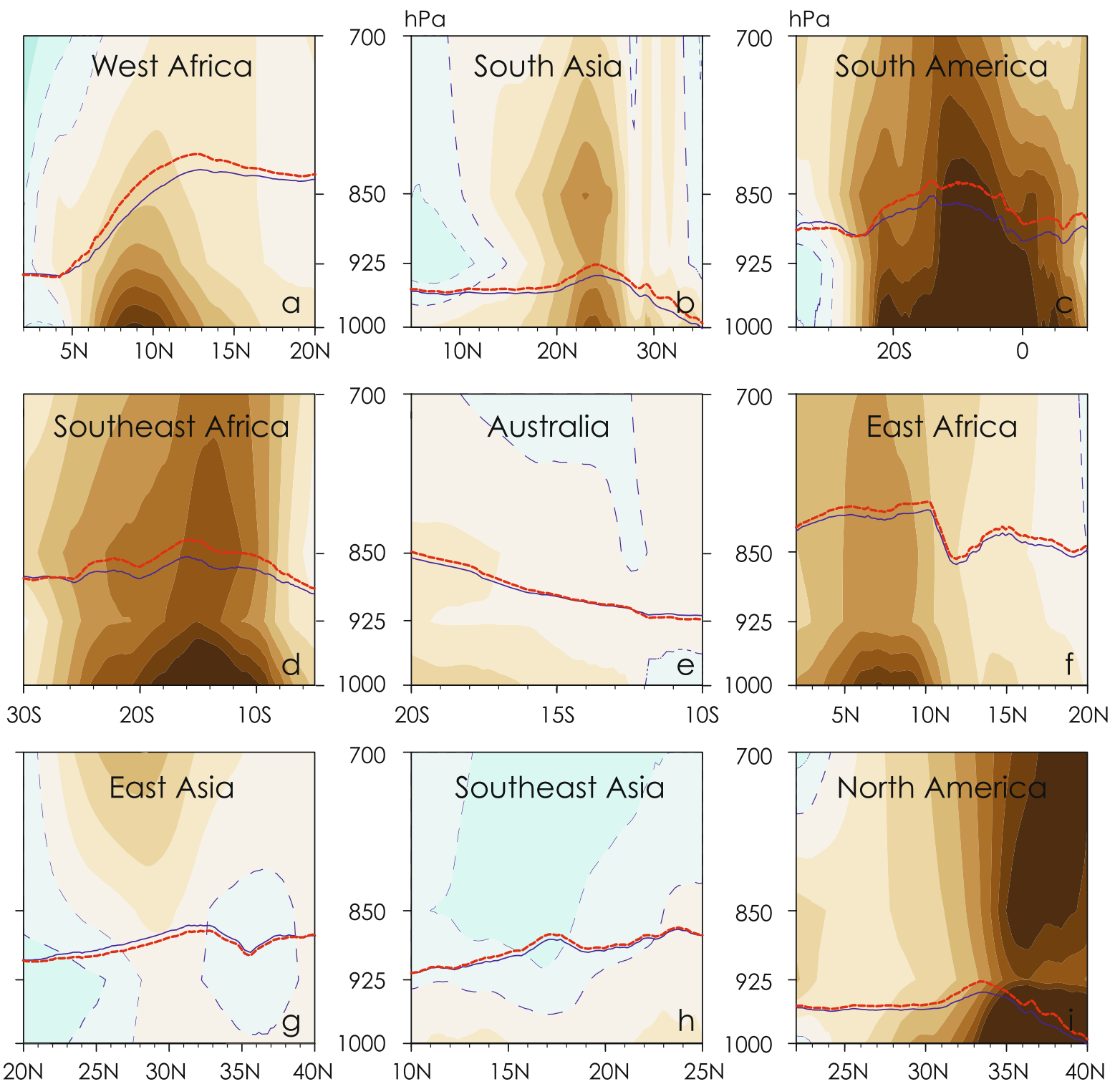

700
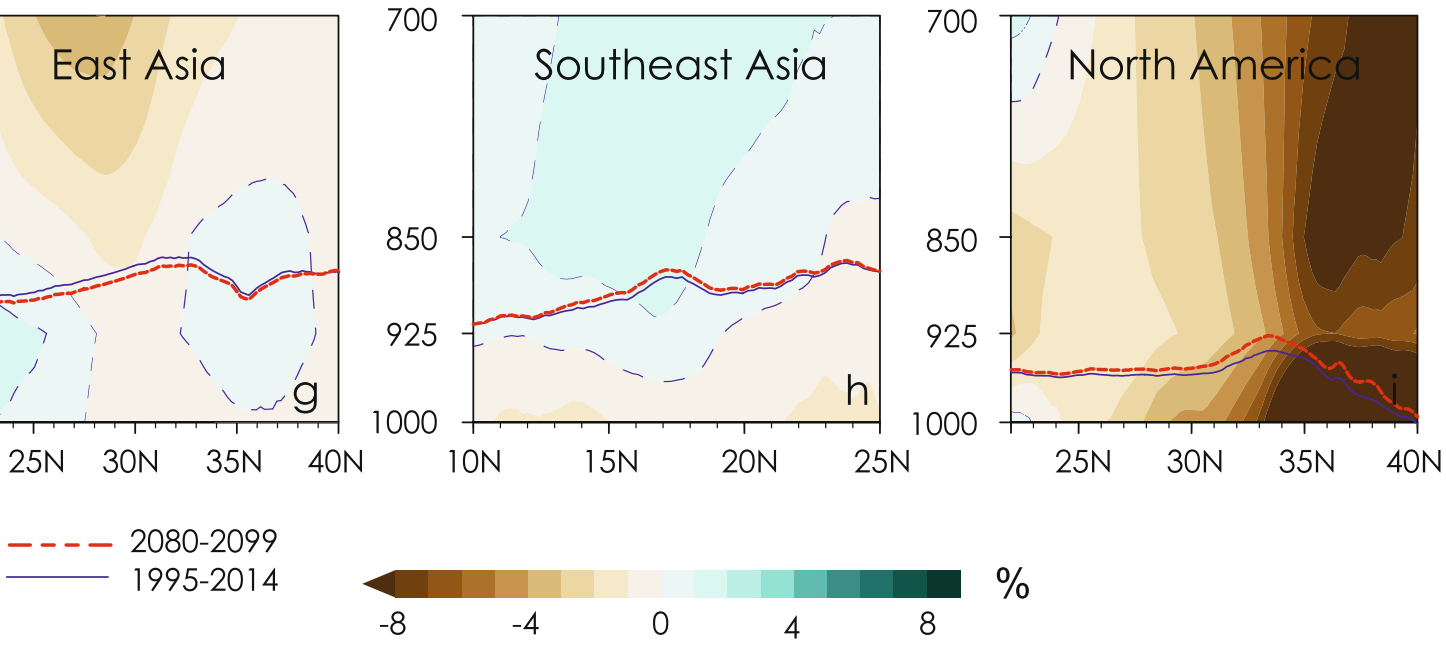

Fig. 12 Changes (2080-2099 minus 1995-2014) in the latitudepressure cross-section of pre-monsoon relative humidity (\%) under RCP8.5 over a West Africa, b South Asia, c South America, d Southeast Africa, e Australia, f East Africa, g East Asia, h Southeast Asia, and i North America. The colored lines in each panel represent

The implications of projected changes in global monsoons at higher levels of radiative forcing under the RCP8.5 are unprecedented. However, our analyses demonstrate the possibility that a substantial change in global monsoons can be avoided under the RCP2.6, highlighting the urgent atmospheric boundary layer height in 1995-2014 (blue) and 2080 2099 (red). The height of atmospheric boundary layer is represented in terms of corresponding atmospheric pressure. All domains are identical to the ones used in Figs. 9 and 10. The pre-monsoon period represents the average over two months prior to the monsoon period

need for steps towards emissions stabilization. Unfortunately, observations suggest that we may already be running out of time as the maximum observed $\mathrm{CO}_{2}$ levels in 2019 (415.7 ppm; https://www.co2.earth/daily-co2) were comparable to the annual average $\mathrm{CO}_{2}$ levels in the RCP8.5 
Zonally Averaged Upper Tropospheric (500mb to $200 \mathrm{mb}$ ) Temperatures

Historical Comparison (1995 to 2014)

ERA5

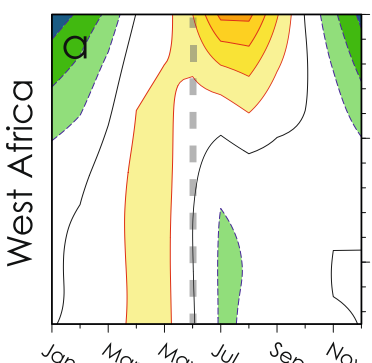

$20 \mathrm{~N}$

$15 \mathrm{~N}$

ON
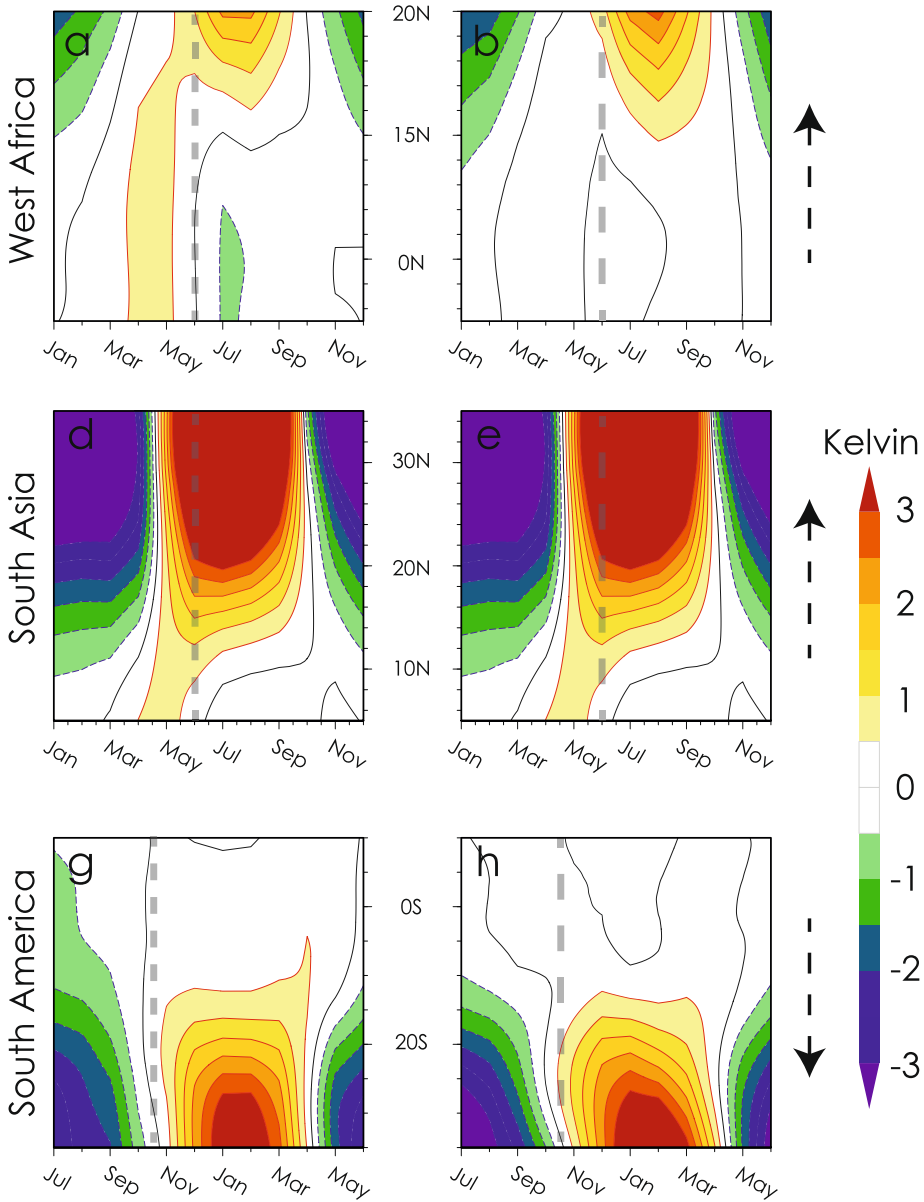

os
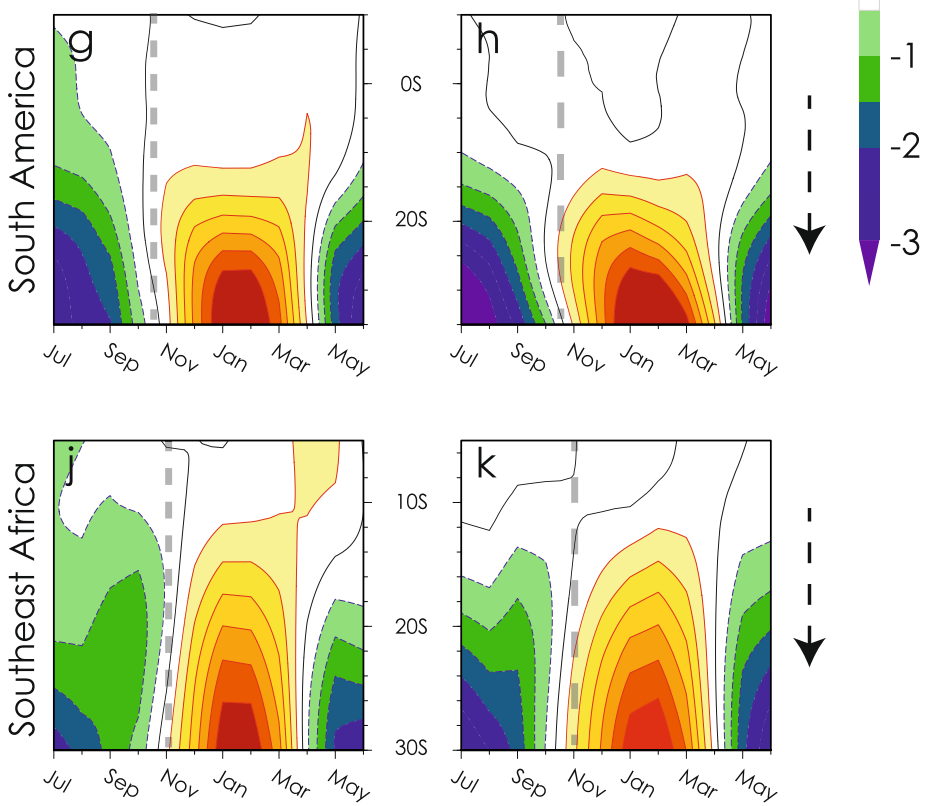

Future Changes (2080 to 2099)
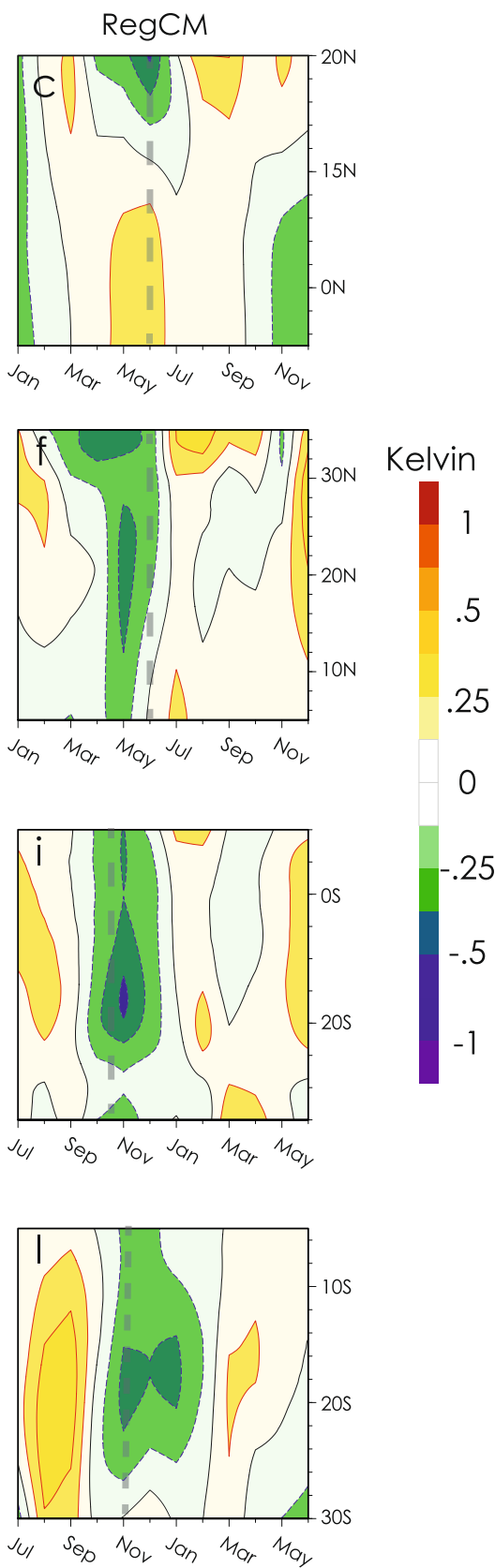

Fig. 13 Departure of zonally averaged monthly upper tropospheric temperatures from the annual mean over West Africa (a-c), South Asia (d-f), South America $(\mathbf{g}-\mathbf{i})$ and Southeast Africa $(\mathbf{j}-\mathbf{l})$. The first and second column show comparisons between ERA5 and RegCM in the reference period (1995-2014). The third column shows the projected changes in the late-century (2080-2099) period under RCP8.5 with respect to the reference period. All domains are identical to the ones used in Fig. 7, except for West Africa, which extends further down to 5S. Black contours represent the zero line. The grey dotted line represents approximate timing of the earliest onset over land and the black arrows represent the direction of the monsoon progression along the latitude over each region 
Zonally Averaged Upper Tropospheric (500mb to $200 \mathrm{mb}$ ) Temperatures

Historical Comparison (1995 to 2014)
ERA5
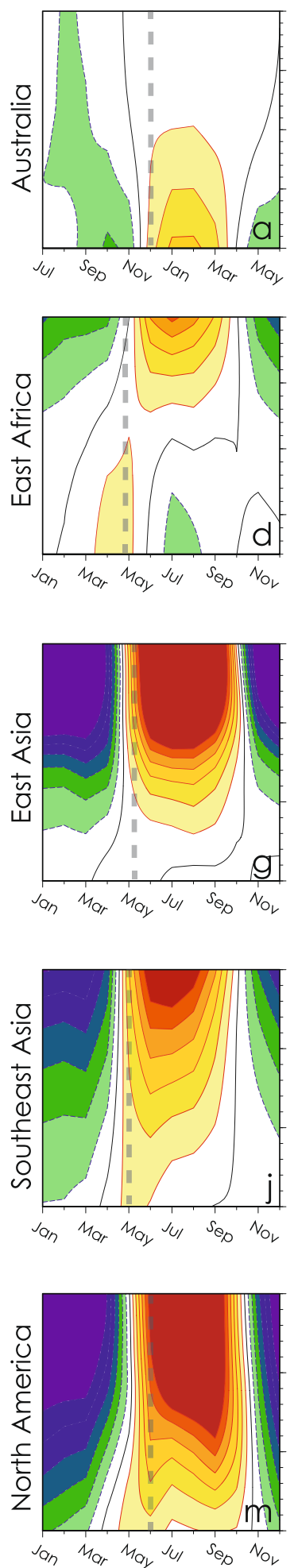

$\operatorname{Reg} C M$
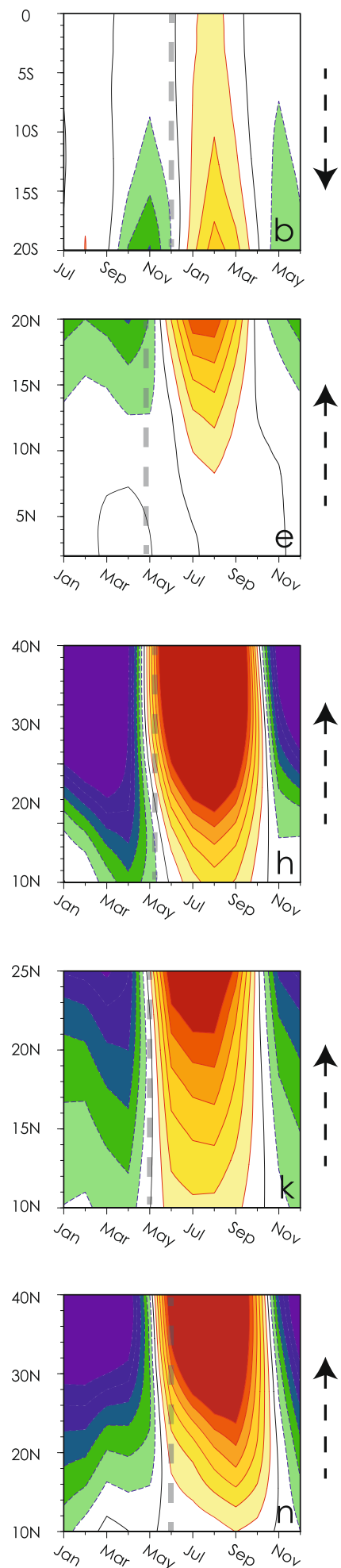

Future Changes (2080 to 2099) $\operatorname{Reg} C M$
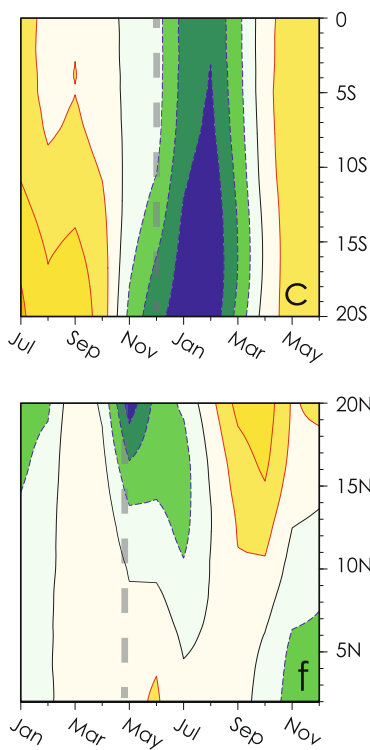

Kelvin Kelvin

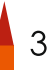

2

.25

0

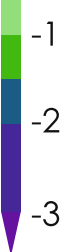

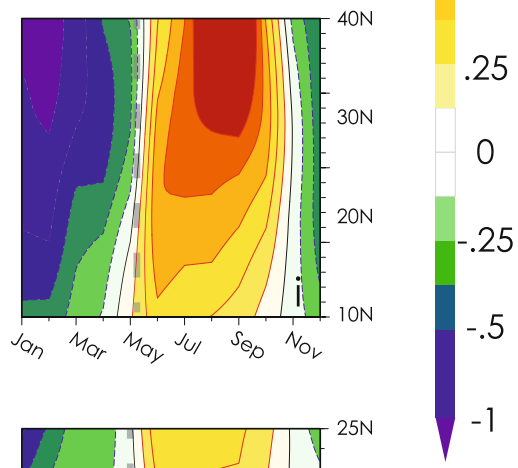
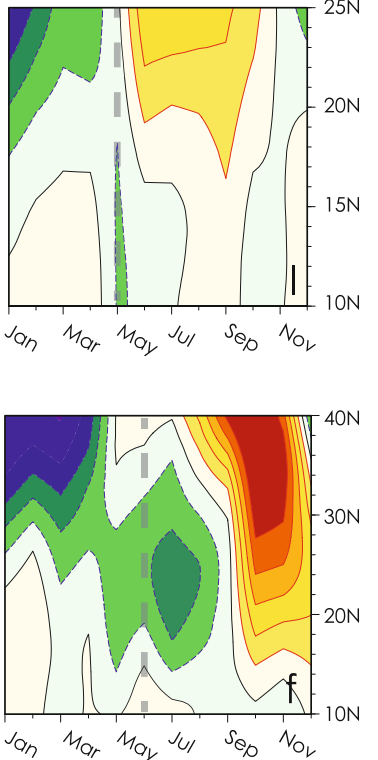

Fig. 14 Same as in Fig. 13, but for Australia (a-c), East Africa (d-f), East Asia $(\mathbf{g}-\mathbf{i})$, Southeast Asia $(\mathbf{j}-\mathbf{l})$ and North America $(\mathbf{m}-\mathbf{f})$. All domains are identical to the ones used in Fig. 7, except for Australia, which extends further north to the equator, and North America, which

extends further down to $10 \mathrm{~N}$. The black contours represent the zero line. The grey dotted line represents the approximate timing of the earliest onset over land and the black arrows represent the direction of the monsoon progression along the latitude over each region 
(412.8 ppm), and the maximum radiative forcing levels in the RCP2.6 will be reached before the 2030s in the RCP8.5 (Meinshausen et al. 2011). Nonetheless, significant deviations from the current emission trajectories should still be able to avoid major catastrophes.

\section{Summary}

In this paper, we have provided, for the first time, a global view of changes in monsoon characteristics based on a large ensemble of high-resolution RegCM4 experiments for two different GHG forcing scenarios. In total, we analyzed nine regional monsoons, including three in the SH (Australia, Southeast Africa, and South America) and six in the NH (East Asia, Southeast Asia, South Asia, East Africa, West Africa, and North America). The evaluations of the RegCM4 ensemble mean demonstrates the ability of the model to reasonably reproduce the inter-hemispheric transition of the monsoon seasons and the evolution of the seasonal monsoon characteristics in different regions.

Monsoon systems around the world are projected to experience unprecedented changes in monsoon precipitation characteristics, including shrinking of the rainy season, delays in monsoon onset and demise, and substantial changes in the magnitude of seasonal precipitation, especially under the high-end RCP8.5 scenario. For this scenario, most of the projected changes become spatially robust and greater than the baseline variability towards the end of the twenty-first century. For instance, presently, the monsoon onset in the SH varies from late October over South America to late November over Southeast Africa and mid-December over Australia. In our simulations the monsoon onset is projected to be delayed by two to eight pentads, with the strongest delay over South America and the weakest over Australia. Similarly, presently, the monsoon onset in the NH varies from early May over East Asia and Southeast Asia to early June over the rest of the $\mathrm{NH}$ monsoon regions, and this is projected to have no spatially robust changes over East Asia and Southeast Asia but to undergo substantial delays over the rest of the $\mathrm{NH}$ monsoon regions, with the strongest delays of five to more than eight pentads occurring over South Asia and Africa. A delay in the monsoon demise is also projected over many regions that experience late monsoon onset, however, the delay in monsoon demise is less than the delay in monsoon onset, which reflects a shrinking of the monsoon rainy seasons. These changes in the regional monsoons are also accompanied by an increase in their seasonality, which is mainly driven by a higher fraction of the annual precipitation during the monsoon seasons. Collectively, these projected changes point towards a substantial drying outside of the monsoon seasons and an intensification of monsoon precipitation within the monsoon seasons.

A robust relationship between the projected pre-monsoon drying and delays in the monsoon onset exists across regional monsoons, as a weakening of latent heat driven atmospheric warming during the pre-monsoon period delays the overturning of atmospheric subsidence in the monsoon regions. Pre-monsoon precipitation is predominantly convective in nature, and it is suppressed as a result of the deepening of the atmospheric boundary layer and a reduction in the relative humidity levels in the lower troposphere. In response to the RCP2.6 forcing, which corresponds to a scenario of strongly reduced GHG emissions by the end of the century, most of the regional monsoons exhibit small changes within the baseline variability. This illustrates the strong added value in reducing emissions for global economies, in particular, of currently poor and more vulnerable tropical countries.

While regional monsoon projections in this study are one of the most detailed to date, there remain a number of outstanding issues that illustrate the need of future work to address them. These include potential impacts of land-use change (Pielke 2005), irrigation systems and water management practices (Devanand et al. 2019), land-ocean-atmosphere feedbacks (Chou et al. 2001), model internal biases (Giorgi and Bi 2000), sensitivity of simulated responses to the choice of driving GCMs (Kjellstrom et al. 2011), and the inter-comparison of RCMs. Finally, finer scale observational datasets are needed to evaluate regional models, particularly in complex terrain areas and in regions where the largest impacts are expected. 
Divergence $\left(\times 10^{6}\right)$ and Vertical Velocity (x 50) Vectors with Vertical Velocity (x 50) as Colored Contours (Changes in RCP8.5 2080 to 2099 w.r.t 1995 to 2014)

Pre-Monsoon

West Africa
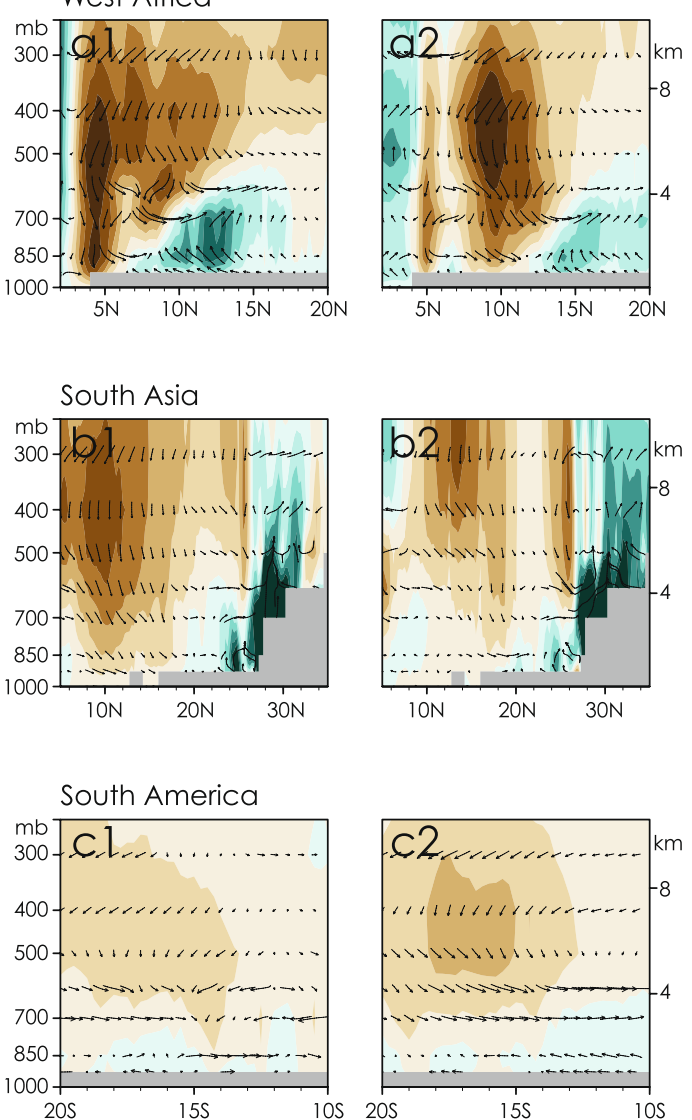

Southeast Africa
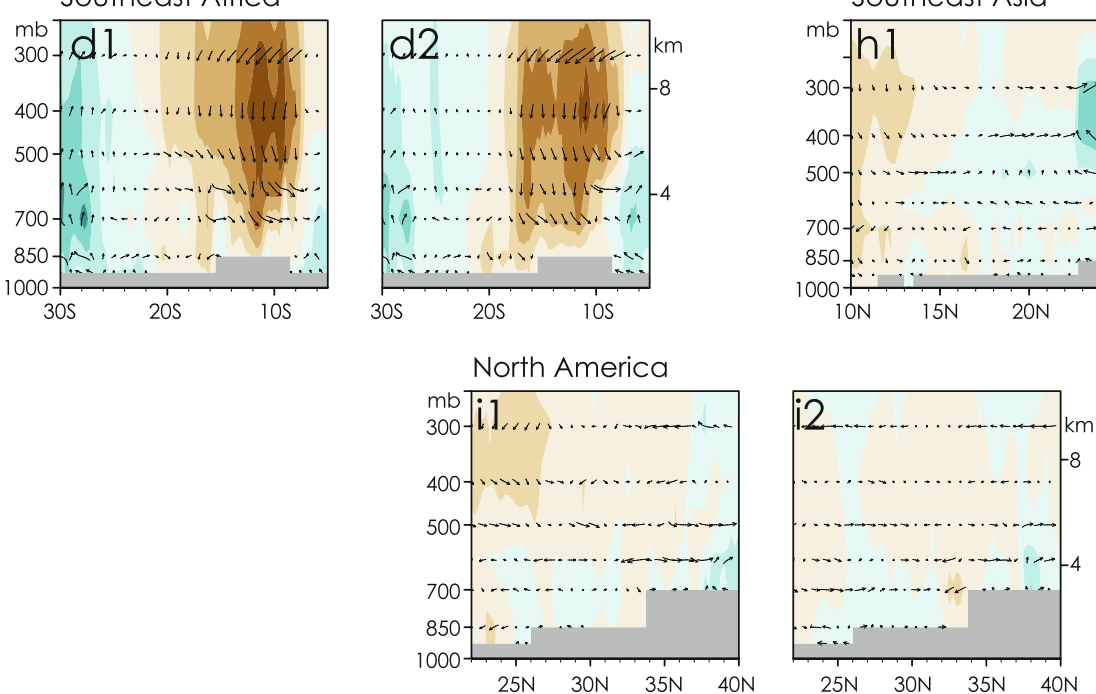

Monsoon
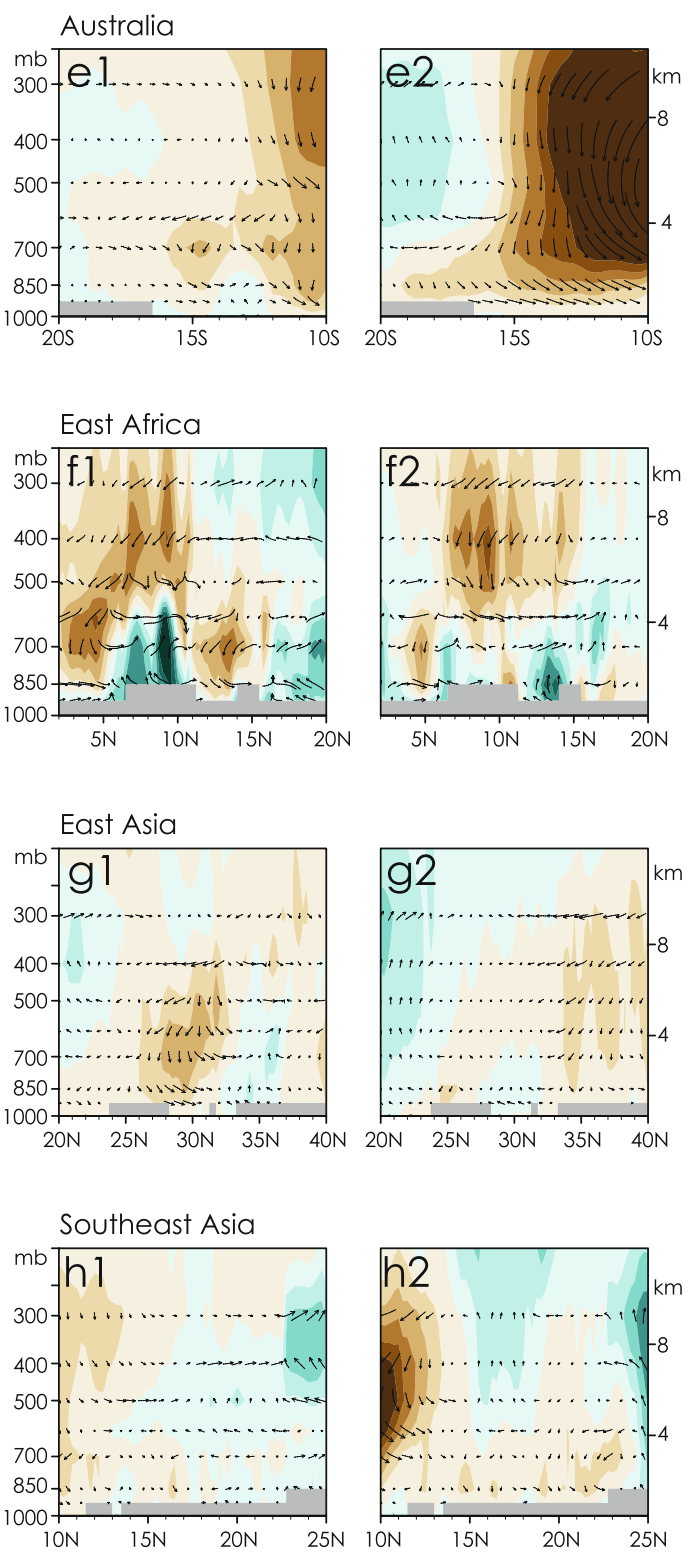

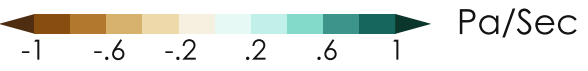


४Fig. 15 Changes in latitude-height cross-section of divergence $(1 / \mathrm{s})$ and vertical pressure velocity $(\mathrm{Pa} / \mathrm{s})$, shown as wind vectors averaged over latitudes used in Fig. 7 and 8. West Africa (a1, a2), South Asia (b1, b2), South America (c1, c2), and Southeast Africa (d1, d2), Australia (e1, e2), East Africa (f1, f2), East Asia (g1, g2), Southeast Asia (h-h2) and North America (i1, i2). Colored contours represent the vertical pressure velocity. Both vertical pressure velocity and divergence have been exaggerated by 50 and $10^{6}$ in all plots. Vertical pressure velocity is multiplied by -1 so that positive values represent an upward motion. The two panels in each case represent the averages over the pre-monsoon and monsoon periods. The pre-monsoon period represents the average over two months prior to the monsoon season

Acknowledgements We thank the two anonymous reviewers for their encouraging comments. Support for model simulations, data storage and analyses are partly provided by the Oak Ridge Leadership Computing Facility at the Oak Ridge National Laboratory (ORNL). M. A. was supported by the National Climate-Computing Research Center, which is located within the National Center for Computational Sciences at the ORNL and supported under a Strategic Partnership Project, 2316-T849-08, between DOE and NOAA. M.S.R would like to thank CNPq-Brazil. E.S.M was supported by the Hong Kong Research Grants Council funded project, GRF16309719. This manuscript has been coauthored by employees of Oak Ridge National Laboratory, managed by UT Battelle, LLC, under contract DE-AC05-00OR22725 with the U.S. Department of Energy. The publisher, by accepting the article for publication, acknowledges that the United States Government retains a non-exclusive, paid-up, irrevocable, world-wide license to publish or reproduce the published form of this manuscript, or allow others to do so, for United States Government purposes. The Department of Energy will provide public access to these results of federally sponsored research in accordance with the DOE Public Access Plan (https ://energy.gov/downloads/doe-public-access-plan).

Funding This study was funded by Oak Ridge National Laboratory (3NOA31MA) and Hong Kong Research Grants Council (GRF16309719).

Open Access This article is licensed under a Creative Commons Attribution 4.0 International License, which permits use, sharing, adaptation, distribution and reproduction in any medium or format, as long as you give appropriate credit to the original author(s) and the source, provide a link to the Creative Commons licence, and indicate if changes were made. The images or other third party material in this article are included in the article's Creative Commons licence, unless indicated otherwise in a credit line to the material. If material is not included in the article's Creative Commons licence and your intended use is not permitted by statutory regulation or exceeds the permitted use, you will need to obtain permission directly from the copyright holder. To view a copy of this licence, visit http://creativecommons.org/licenses/by/4.0/.

\section{References}

Akumaga U, Tarhule A (2018) Projected changes in intra-season rainfall characteristics in the Niger River Basin, West Africa. Atmosphere 9(12):497. https://doi.org/10.3390/atmos9120497

Ambrizzi T et al (2019) The state of the art and fundamental aspects of regional climate modeling in South America. Ann N York Acad Sci 1436(1):98-120

An ZS et al (2015) Global monsoon dynamics and climate change. Ann Rev Earth Planet Sci 43:29-77
Arias PA, Fu R, Mo KC (2012) Decadal variation of rainfall seasonality in the North American monsoon region and its potential causes. J Clim 25(12):4258-4274

Ashfaq M, Shi Y, Tung WW, Trapp RJ, Gao XJ, Pal JS, Diffenbaugh NS (2009) Suppression of south Asian summer monsoon precipitation in the 21st century. Geophys Res Lett 36(1):L01704L01709. https://doi.org/10.1029/2008g1036500

Ashfaq M et al (2016) High-resolution ensemble projections of nearterm regional climate over the continental United States. J Geophys Res Atmos 121(17):9943-9963

Ashfaq M et al (2017) Sources of errors in the simulation of south Asian summer monsoon in the CMIP5 GCMs. Clim Dyn 49(1-2):193-223

Beegle KG, Olinto P, Sobrado CE, Uematsu H (2013) The state of the poor: where are the poor, where is extreme poverty harder to end, and what is the current profile of the world's poor? Report no. 81801. World Bank, Washington DC. Retrieved from http:// documents.worldbank.org/curated/en/311511468326955970/ The-state-of-the-poor-where-are-the-poor-where-is-extremepoverty-harder-to-end-and-what-is-the-current-profile-of-theworlds-poor

Benitez MA (2009) Climate change could affect mosquito-borne diseases in Asia. Lancet 373(9669): 1070

Bentsen $\mathrm{M}$ et al (2013) Norwegian earth system model, NorESM1-MPart 1: description and basic evaluation of the physical climate. Geosci Model Devel 6(3):687-720

Biasutti M (2019) Rainfall trends in the African Sahel: characteristics, processes, and causes. Wiley Interdisc Rev Clim Change 10(4):e591. https://doi.org/10.1002/wcc.591

Biasutti M et al (2018) Global energetics and local physics as drivers of past, present and future monsoons. Nat Geosci 11(6):392

Bollasina MA et al (2014) Contribution of local and remote anthropogenic aerosols to the twentieth century weakening of the South Asian Monsoon. Geophys Res Lett 41(2):680-687

Bombardi RJ, Carvalho LMV (2009) IPCC global coupled model simulations of the South America monsoon system. Clim Dyn 33(7-8):893-916

Bretherton CS, McCaa JR (2004) Grenier H (2004) A new parameterization for shallow cumulus convection and its application to marine subtropical cloud-topped boundary layers. Part I: Description and 1D results. Mon Weather Rev 132(4):864-882

Bridhikitti A (2019) Multi-decadal trends and oscillations of Southeast Asian monsoon rainfall in northern Thailand. Songklanakarin J Sci Technol 41(1):74-80

Bukovsky MS, Gochis DJ, Mearns LO (2013) Towards assessing NARCCAP regional climate model credibility for the North American Monsoon: current climate simulations. J Clim 26(22):8802-8826

Copernicus Climate Change Service (C3S) (2017) ERA5: Fifth generation of ECMWF atmospheric reanalyses of the global climate. Retrieved from https://cds.climate.copernicus.eu/cdsapp\#!/home

Carvalho LMV, Cavalcanti IFA (2016) The South American Monsoon System (SAMS). In: Carvalho L, Jones C (eds) The monsoons and climate change. Springer, Cham

Castro CL, McKee TB, Pielke RA (2001) The relationship of the North American monsoon to tropical and North Pacific Sea surface temperatures as revealed by observational analyses. J Clima 14(24):4449-4473

Cavazos T et al (2020) Climatic trends and regional climate models intercomparison over the CORDEX-CAM (Central America, Caribbean, and Mexico) domain. Int J Climatol 40(3):1396-1420

Chou C, Neelin JD (2004) Mechanisms of global warming impacts on regional tropical precipitation. J Clim 17(13):2688-2701

Chou C, Neelin JD, Su H (2001) Ocean-atmosphere-land feedbacks in an idealized monsoon. Quart J R Meteorol Soc 127(576):1869-1891 
Christensen JH, Krishna Kumar K, Aldrian E, An S-I, Cavalcanti IFA, de Castro M, Dong W, Goswami P, Hall A, Kanyanga JK, Kitoh A, Kossin J, Lau N-C, Renwick J, Stephenson DB, Xie S-P, Zhou T (2013) Climate phenomena and their relevance for future regional climate change. In: Stocker TF, Qin D, Plattner G-K, Tignor M, Allen SK, Boschung J, Nauels A, Xia Y, Bex V, Midgley PM (eds) Climate change 2013: the physical science basis. Contribution of working group I to the fifth assessment report of the intergovernmental panel on climate change. Cambridge University Press, Cambridge, UK/New York, NY, USA

Colorado-Ruiz G et al (2018) Climate change projections from Coupled Model Intercomparison Project phase 5 multi-model weighted ensembles for Mexico, the North American monsoon, and the mid-summer drought region. Int J Climatol 38(15):5699-5716

Cook BI, Seager R (2013) The response of the North American Monsoon to increased greenhouse gas forcing. J Geophys Res Atmos 118(4):1690-1699

Dash AP et al (2013) Emerging and re-emerging arboviral diseases in Southeast Asia. J Vector Borne Diseases 50(2):77-84

de Camargo MBP (2010) The impact of climatic variability and climate change on arabic coffee crop in Brazil. Bragantia. https://doi. org/10.1590/S0006-7052010000100030

de Queiroz AR et al (2019) Hydropower revenues under the threat of climate change in Brazil. Renew Energy 133:873-882

Devanand A et al (2019) Choice of irrigation water management practice affects Indian summer monsoon rainfall and its extremes. Geophys Res Lett 46(15):9126-9135

Dhiman RC et al (2010) Climate change and threat of vector-borne diseases in India: are we prepared? Parasitol Res 106(4):763-773

Diallo I et al (2014) Simulation of the West African monsoon onset using the HadGEM3-RA regional climate model. Clim Dyn 43(3-4):575-594

Diallo I et al (2016) Projected changes of summer monsoon extremes and hydroclimatic regimes over West Africa for the twenty-first century. Clim Dyn 47(12):3931-3954

Diffenbaugh NS, Ashfaq M, Scherer M (2011) Transient regional climate change: analysis of the summer climate response in a high-resolution, century-scale ensemble experiment over the continental United States. J Geophys Res Atmos. https://doi. org/10.1029/2011jd016458

Dong BW, Sutton R (2015) Dominant role of greenhouse-gas forcing in the recovery of Sahel rainfall. Nat Clim Change 5(8):757-U173

Donner LJ et al (2011) The dynamical core, physical parameterizations, and basic simulation characteristics of the atmospheric component AM3 of the GFDL Global Coupled Model CM3. J Clim 24(13):3484-3519

Dunning CM, Allan RP, Black E (2017) Identification of deficiencies in seasonal rainfall simulated by CMIP5 climate models. Environ Res Lett 12(11):114001. https://doi.org/10.1088/1748-9326/ aa869e

Eckstein D, Künzel V, Schäfer L, Winges M (2020) Global climate extreme index 2020, Who suffers most from extreme weather events? Weather Related Loss Events in 2018 and 1999 to 2018, Briefing paper, GermanWatch. www.germanwatch.org/en/cri

Emanuel KA (1991) A scheme for representing cumulus convection in large-scale models. J Atmos Sci 48(21):2313-2335

Feng X, Porporato A, Rodriguez-Iturbe I (2013) Changes in rainfall seasonality in the tropics. Nat Clim Change 3(9):811-815

Fotso-Nguemo TC et al (2017) On the added value of the regional climate model REMO in the assessment of climate change signal over Central Africa. Clim Dyn 49(11-12):3813-3838

Fuentes-Franco R et al (2014) Assessment of RegCM4 simulated interannual variability and daily-scale statistics of temperature and precipitation over Mexico. Clim Dyn 42(3-4):629-647

Gallego D, Garcia-Herrera R, Pena-Ortiz C, Ribera P (2017) The steady enhancement of the Australian summer monsoon in the last 200 years. Sci Rep 7:16166. https://doi.org/10.1038/s4159 8-017-16414-1

Ganguly D, Rasch PJ, Wang HL, Yoon JH (2012) Climate response of the South Asian monsoon system to anthropogenic aerosols. J Geophys Res Atmos. https://doi.org/10.1029/2012jd017508

Gao XJ et al (2017) Performance of RegCM4 over major river basins in China. Adv Atmos Sci 34(4):441-455

Geil KL, Serra YL, Zeng XB (2013) Assessment of CMIP5 model simulations of the North American monsoon system. J Clim 26(22):8787-8801

Giorgi F (2019) Thirty years of regional climate modeling: where are we and where are we going next? J Geophys Res Atmos 124(11):5696-5723

Giorgi F, Bi XQ (2000) A study of internal variability of a regional climate model. J Geophys Res Atmos 105(D24):29503-29521

Giorgi F, Gutowski WJ (2015) Regional dynamical downscaling and the CORDEX initiative. Annu Rev Environ Resour 40:467-490

Giorgi F, Jones C, Asrar GR (2009) Addressing climate information needs at the regional level: the CORDEX framework. WMO Bull 58(3):176-183

Giorgi F et al (2012) RegCM4: model description and preliminary tests over multiple CORDEX domains. Clim Res 52(1):7-29

Grodsky SA, Carton JA (2001) Coupled land/atmosphere interactions in the West African Monsoon. Geophys Res Lett 28(8):1503-1506

Harris I et al (2014) Updated high-resolution grids of monthly climatic observations-the CRU TS3.10 Dataset. Int J Climatol 34(3):623-642

Held IM, Hou AY (1980) Nonlinear axially symmetric circulations in a nearly inviscid atmosphere. J Atmos Sci 37(3):515-533. https://doi.org/10.1175/1520-0469(1980)037\%3C0515:NASCI A\%3E2.0.CO;2

Holtslag AAM, Debruijn EIF, Pan HL (1990) A high-resolution airmass transformation model for short-range weather forecasting. Mon Weather Rev 118(8):1561-1575

Hsu P, Li T, Luo J-J, Murakami H, Kitoh A, Zhao M (2012) Increase of global monsoon area and precipitation under global warming: a robust signal? Geophys Res Lett 39:L06701. https://doi. org/10.1029/2012GL051037

Huffman GJ, Bolvin DT, Adler RF (2016) GPCP version 1.2 onedegree daily precipitation data set. In: Research NCFA (ed) Research data archive. NCFA Research, Boulder

Hurley JV, Boos WR (2015) A global climatology of monsoon lowpressure systems. Quart J R Meteorol Soc 141(689):1049-1064

Jiang YQ et al (2013) A numerical study of the effect of different aerosol types on East Asian summer clouds and precipitation. Atmos Environ 70:51-63

Jones C, Carvalho LMV (2013) Climate change in the South American monsoon system: present climate and CMIP5 projections. J Clim 26(17):6660-6678

Jones CD et al (2011) The HadGEM2-ES implementation of CMIP5 centennial simulations. Geosci Model Devel 4(3):543-570

Kain JS (2004) The Kain-Fritsch convective parameterization: an update. J Appl Meteorol 43(1):170-181

Kain JS, Fritsch JM (1990) A one-dimensional entraining detraining plume model and its application in convective parameterization. J Atmos Sci 47(23):2784-2802

Kitoh A et al (2013) Monsoons in a changing world: a regional perspective in a global context. J Geophys Res Atmos 118(8):3053-3065

Kjellstrom E et al (2011) 21st century changes in the European climate: uncertainties derived from an ensemble of regional climate model simulations. Tellus Series Dyn Meteorol Oceanogr 63(1):24-40

Kumi N, Abiodun BJ (2018) Potential impacts of $1.5^{\circ} \mathrm{C}$ and $2{ }^{\circ} \mathrm{C}$ global warming on rainfall onset, cessation and length of rainy season in West Africa. Environ Res Lett 13(8):055009 
Langenbrunner B et al (2019) Why does Amazon precipitation decrease when tropical forests respond to increasing $\mathrm{CO}_{2}$ ? Earths Future 7(4):450-468

Lee JY, Wang B (2014) Future change of global monsoon in the CMIP5. Clim Dyn 42(1-2):101-119

Li DL (2017) Added value of high-resolution regional climate model: selected cases over the Bohai Sea and the Yellow Sea areas. Int J Climatol 37(1):169-179

Li CF, Yanai M (1996) The onset and interannual variability of the Asian summer monsoon in relation to land sea thermal contrast. J Clim 9(2):358-375

Lindzen RS, Hou AY (1988) Hadley circulations for zonally averaged heating centered off the equator. J Atmos Sci 45(17):2416-2427

Llopart M, Reboita MS, da Rocha RP (2019) Assessment of multimodel climate projections of water resources over South America CORDEX domain. Clim Dyn 54:99-116. https://doi. org/10.1007/s00382-019-04990-Z

Marengo JA, Tomasella J, Alves LM, Soares WR, Rodriguez DA (2011) The drought of 2010 in the context of historical droughts in the Amazon region. Geophys Res Lett. https://doi. org/10.1029/2011g1047436

Mariotti L et al (2014) Seasonal and intraseasonal changes of African monsoon climates in 21 st century CORDEX projections. Clim Change 125(1):53-65

Martinez-Castro D et al (2006) Sensitivity studies of the RegCM3 simulation of summer precipitation, temperature and local wind field in the Caribbean Region. Theor Appl Climatol 86(1-4):5-22

Mei R et al (2015) Dominating controls for wetter South Asian summer monsoon in the twenty-first century. J Clim 28(8):3400-3419

Meinshausen $\mathrm{M}$ et al (2011) The RCP greenhouse gas concentrations and their extensions from 1765 to 2300 . Clim Change 109(1-2):213-241

Misra V (2008) Coupled interactions of the monsoons. Geophys Res Lett. https://doi.org/10.1029/2008gl033562

Neelin JD, Chou C, Su H (2003) Tropical drought regions in global warming and El Nino teleconnections. Geophys Res Lett. https ://doi.org/10.1029/2003gl018625

New M, Hulme M, Jones P (1999) Representing twentieth-century space-time climate variability. Part I: Development of a 1961-1990 mean monthly terrestrial climatology. J Clim 12(3):829-856

Nijssen B et al (2001) Predicting the discharge of global rivers. J Clim 14(15):3307-3323

Pal JS, Small EE, Eltahir EAB (2000) Simulation of regional-scale water and energy budgets: representation of subgrid cloud and precipitation processes within RegCM. J Geophys Res Atmos 105(D24):29579-29594

Pascale $S$ et al (2017) Weakening of the North American monsoon with global warming. Nat Clim Change 7(11):806

Pascale S et al (2019) Current and future variations of the monsoons of the Americas in a warming climate. Curr Clim Change Rep $5(3): 125-144$

Pielke RA (2005) Land use and climate change. Science 310(5754):1625-1626

Polson D et al (2014) Decreased monsoon precipitation in the Northern Hemisphere due to anthropogenic aerosols. Geophys Res Lett 41(16):6023-6029

Qiu L, Im ES, Hur J, Shim KM (2019) Added value of very high resolution climate simulations over South Korea using WRF modeling system. Clim Dyn. https://doi.org/10.1007/s00382-019-04992-x

Racherla PN, Shindell DT, Faluvegi GS (2012) The added value to global model projections of climate change by dynamical downscaling: a case study over the continental US using the GISSModelE2 and WRF models. J Geophys Res Atmos. https://doi. org/10.1029/2012jd018091
Ramage CS (1971) Monsoon meteorology, vol 15. New York Academic Press, New York

Rastogi D et al (2018) Characteristics of Bay of Bengal monsoon depressions in the 21 st century. Geophys Res Lett 45(13):6637-6645

Reboita MS, da Rocha RP, Dias CG, Ynoue RY (2014) Climate projections for South America: RegCM3 driven by HadCM3 and ECHAM5. Adv Meteorol. https://doi.org/10.1155/2014/376738

Rodwell MJ, Hoskins BJ (2001) Subtropical anticyclones and summer monsoons. J Clim 14(15):3192-3211

Roehrig R et al (2013) The present and future of the West African Monsoon: a process-oriented assessment of CMIP5 simulations along the AMMA transect. J Clim 26(17):6471-6505

Rojas M et al (2019) Emergence of robust precipitation changes across crop production areas in the 21st century. Proc Natl Acad Sci USA 116(14):6673-6678

Schroth G et al (2016) Vulnerability to climate change of cocoa in West Africa: patterns, opportunities and limits to adaptation. Sci Total Environ 556:231-241

Schumacher C, Houze RA (2003) Stratiform rain in the tropics as seen by the TRMM precipitation radar. J Clim 16(11):1739-1756

Sena ET et al (2018) Reduced wet-season length detected by satellite retrievals of cloudiness over Brazilian Amazonia: a new methodology. J Clim 31(24):9941-9964

Seth A et al (2013) CMIP5 projected changes in the annual cycle of precipitation in monsoon regions. J Clim 26(19):7328-7351

Singh D, Ghosh S, Roxy MK, McDermid S (2019) Indian summer monsoon: extreme events, historical changes, and role of anthropogenic forcings. Wiley Interdisc Rev Clim Change. https://doi. org/10.1002/wcc. 571

Sperber K et al (2013) The Asian summer monsoon: an intercomparison of CMIP5 vs. CMIP3 simulations of the late 20th century. Clim Dyn 41(9-10):2711-2744

Stevens B et al (2013) Atmospheric component of the MPI-M earth system model: ECHAM6. J Adv Model Earth Syst 5(2):146-172

Sun XM, Vizy EK, Cook KH (2019) Land-atmosphere-ocean interactions in the southeastern Atlantic: interannual variability. Clim Dyn 52(1-2):539-561

Sylla MB, Diallo I, Pal JS (2013) West African monsoon in state-ofthe-science regional climate models. In: Climate variabilityregional and thematic patterns. https://doi.org/10.5772/55140

Sylla MB et al (2015) Projected changes in the annual cycle of highintensity precipitation events over West Africa for the late twenty-first century. J Clim 28(16):6475-6488

Taylor KE, Stouffer RJ, Meehl GA (2012) An overview of Cmip5 and the experiment design. Bull Am Meteorol Soc 93(4):485-498

Thomas L et al (2018) Convective environment in pre-monsoon and monsoon conditions over the Indian subcontinent: the impact of surface forcing. Atmos Chem Phys 18(10):7473-7488

Thorncroft CD et al (2011) Annual cycle of the West African monsoon: regional circulations and associated water vapour transport. Quart J R Meteorol Soc 137(654):129-147

Tiedtke M (1996) An extension of cloud-radiation parameterization in the ECMWF model: the representation of subgrid-scale variations of optical depth. Mon Weather Rev 124(4):745-750

Torma C, Giorgi F, Coppola E (2015) Added value of regional climate modeling over areas characterized by complex terrainPrecipitation over the Alps. J Geophys Res Atmos 120(9):3957-3972

Torres-Alavez A, Cavazos T, Turrent C (2014) Land-sea thermal contrast and intensity of the North American monsoon under climate change conditions. J Clim 27(12):4566-4580

Turrent C, Cavazos T (2009) Role of the land-sea thermal contrast in the interannual modulation of the North American monsoon. Geophys Res Lett. https://doi.org/10.1029/2008g1036299

van Vuuren DP et al (2011) The representative concentration pathways: an overview. Clim Change 109(1-2):5-31 
Wang B, Wu RG, Li T (2003) Atmosphere-warm ocean interaction and its impacts on Asian-Australian monsoon variation. J Clim 16(8):1195-1211

Wang B et al (2012) Recent change of the global monsoon precipitation (1979-2008). Clim Dyn 39(5):1123-1135

Watanabe $\mathrm{M}$ et al (2010) Improved climate simulation by MIROC5. Mean states, variability, and climate sensitivity. J Clim 23(23):6312-6335

Webster PJ et al (1998) Monsoons: processes, predictability, and the prospects for prediction. J Geophys Res Oceans 103(C7):14451-14510

Yasunari T (2007) Role of land-atmosphere interaction on Asian monsoon climate. J Meteorol Soc Jpn 85b:55-75

Yin L et al (2013) How well can CMIP5 simulate precipitation and its controlling processes over tropical South America? Clim Dyn 41(11-12):3127-3143

Zeng XB, Zhao M, Dickinson RE (1998) Intercomparison of bulk aerodynamic algorithms for the computation of sea surface fluxes using TOGA COARE and TAO data. J Clim 11(10):2628-2644
Zhan YJ, Ren GY, Yang S (2018) Change in precipitation over the Asian continent from 1901 to 2016 based on a new multi-source dataset. Clim Res 76(1):41-57

Zhang HQ (2010) Diagnosing Australia-Asian monsoon onset/ retreat using large-scale wind and moisture indices. Clim Dyn 35(4):601-618

Zhang WX, Zhou TJ (2019) Significant increases in extreme precipitation and the associations with global warming over the global land monsoon regions. J Clim 32(24):8465-8488

Zhu YL et al (2011) Recent changes in the summer precipitation pattern in East China and the background circulation. Clim Dyn 36(7-8):1463-1473

Publisher's Note Springer Nature remains neutral with regard to jurisdictional claims in published maps and institutional affiliations. 